\title{
Access to Capital in Rural Thailand: An Estimated Model of Formal vs. Informal Credit
}

\author{
Xavier Giné* \\ The World Bank
}

\begin{abstract}
The aim of this paper is to understand the mechanism underlying access to credit. We focus on two important aspects of rural credit markets in Thailand. First, moneylenders and other informal lenders coexist with formal lending institutions such as government or commercial banks, and more recently, micro-lending institutions. Second, potential borrowers presumably face sizable transaction costs obtaining external credit. We develop and estimate a model based on limited enforcement and transaction costs that provides a unified view of these facts. The results show that the limited ability of banks to enforce contracts, more than transaction costs, is crucial in understanding the observed diversity of lenders.
\end{abstract}

JEL Code: O12

Keywords: Credit Constraints, Transaction Costs, Maximum Likelihood.

\section{Introduction}

Most productive activities entail a time lag between the time when inputs are acquired and the time when output is obtained. For this reason, when self-financing is not possible, the inputs must be purchased using credit from financial institutions or informal

*Email: xgine@worldbank.org. This paper is a revised version of my PhD thesis. At different stages, I benefitted from the valuable comments of Chris Ahlin, Orazio Attanasio, Paco Buera, Pedro Carneiro, Maitreesh Ghatak, Joe Kaboski, Stefan Klonner, Robert Townsend, Chris Udry, Ivan Werning, Luigi Zingales and many workshop participants. All errors are my own. 
sources. The financial contracts available in rural areas vary substantially depending on the characteristics of the borrowers and lenders and the type of input being financed. Typical examples include small collateral-free and interest-free loans between friends and relatives, collateralized loans from commercial banks, and loans from moneylenders with no collateral requirements but relatively high interest rates.

This last form of lending has traditionally been viewed as unfair, with lenders taking advantage of their position to exploit the poorer borrowers. This view is at the heart of the policy interventions of several governments and NGOs in developing countries. These interventions devote considerable resources to helping supply credit to poor farmers and entrepreneurs who are otherwise denied formal credit. From the experience of countries in Asia, Africa and Latin America, several case studies have come to challenge this old view of informal finance and have questioned the effectiveness of such policies. Siamwalla et al. (1993) and Bell (1993) have shown that, despite the injection of formal credit, informal finance is still used and the interest rates charged have not been affected by the increased presence of formal credit. ${ }^{1}$

In addition, two often neglected pieces of evidence of the behavior of farmers and businesses in rural Thailand seem to render this traditional view overly simplistic. First, borrowing businesses and farms with a larger fraction of assets that can be used as collateral tend to be more active in the formal credit market. ${ }^{2}$ Second, borrowers are often customers in both the formal and informal credit markets. ${ }^{3}$

The literature has taken two distinct approaches to modelling the coexistence of formal and informal lenders. The first assumes that only informal lenders have access to institutional credit who then re-lend to poorer borrowers. The work by Hoff and Stiglitz (1997), Bose (1998) and Floro and Ray (1996) follow this approach. ${ }^{4}$ The second considers formal institutions competing directly with informal lenders. In this strand,

\footnotetext{
${ }^{1}$ On this point see also the collection of articles in Von Pischke, Adams and Donald (1983) and Braverman and Guasch (1986, 1993), Hoff and Stiglitz (1993), Besley (1994) and the book by Armendáriz de Aghion and Morduch (2004).

${ }^{2}$ This point was also developed in the context of Thailand by Feder et al. (1988) and Feder (1993). They find that farmers with titled land have greater access to institutional credit. The land title enables the owner to sell, transfer and legally mortgage the land, and it is used as collateral.

${ }^{3}$ Siamwalla et al. (1993) document that $10 \%$ of households were active clients of both formal and informal sources. However, Udry (1993) and Aryeetey (1997) find little evidence of this in rural Africa. We do not claim that this fact is pervasive across developing countries but it is relevant in our country of study, Thailand.

${ }^{4}$ Another model related to this approach is presented in Ghosh and Ray (1999). They focus on loan enforceability when credit histories are not available to (informal) lenders.
} 
several theoretical explanations have been offered to explain why some households decide to resort to multiple creditors. Bell et al. (1997) argue that an imposed limit on the amount of credit that formal institutions can grant may trigger some constrained borrowers to turn to the informal sector for additional credit. For the particular case of India, Kochar (1997) evaluates the empirical plausibility of this argument and finds little evidence of credit constraints. Jain (1999) and Conning (1996, 1998) postulate that if informal lenders have an informational advantage, formal lenders will screen borrowers by partially financing the project, thus forcing the borrower to resort to an informal lender. This way, banks ensure that the project will be monitored.

Also implicit in the discussion of rural credit markets is the notion that impediments to trade or transaction costs may be important. Indeed, in villages without formal credit institutions, potential clients spend time and money every time they travel to the closest branch. Sometimes, it takes several trips before the loan is granted. In contrast, moneylenders usually live in the same village and will often themselves visit their clients thereby becoming more accessible.

In this paper we develop a model that provides a unified view of the facts mentioned above and whose tractability allows a structural estimation. The model is based on two key features. First, in the spirit of Townsend $(1978,1983)$ and Greenwood and Jovanovic (1990), access to credit is modelled explicitly by assuming that a fixed cost must be foregone in order to obtain external credit. Second, we assume that banks have limited ability to enforce credit contracts. Suppose that a productive project requires an investment in both fixed and working capital. The difference between both types of capital is that fixed capital remains after production has taken place and hence it can be used as collateral, while working capital is fungible and transformed into output. ${ }^{5}$ In addition, suppose that bank clients have the option to default on the contract before producing, in which case they keep the working capital but lose all savings deposited at the bank and the fixed capital, which is seized. This imperfect enforceability effectively imposes a maximum amount of working capital that the bank is willing to lend.

In this scenario, some borrowers may find it profitable to seek an informal lender for additional working capital. If the productive assets that households use differ in the ratio of working to fixed capital, banks will tend to finance entrepreneurs whose technology

\footnotetext{
${ }^{5}$ We could also think of fixed capital as assets with relatively high scrap value, perhaps due to a well-functioning secondary market.
} 
is intensive in fixed capital, whereas entrepreneurs that require relatively more working capital, will be financed primarily by informal lenders.

In addition, if the transaction costs of accessing formal finance are large, households that need little credit will tend to rely on informal lenders whereas those with large credit needs will be better off incurring the fixed costs in order to have access to a lower cost of capital. ${ }^{6}$

Empirical research on rural credit markets faces the problem that the combination of unobserved heterogeneity and of endogenous matching of agents into borrowing from different lenders can create selection biases on the parameters of interest. ${ }^{7}$.

The approach taken here differs from that of Bell et al. (1997), Kochar (1997) and Conning (1996) and resembles Key (1998) in that we estimate the likelihood of borrowing from each source as dictated by the structure of the model. This way, we are able to assess how important enforcement problems vis à vis transaction costs are in the overall picture of credit markets.

The data used come from a cross-section survey conducted in Thailand in 1997, an interesting country because despite the growth episode experienced in the 1980s, formal credit is still limited in rural areas. ${ }^{8,9}$

The estimation results raise several points. First, there are disparities in the cost of accessing different lenders: while the estimated cost of accessing a formal institution is on average US\$30, the cost of accessing an informal source is negligible. Second, the cost of accessing formal finance depends on the characteristics of the household, such as the proximity to the bank or whether the household has a savings account. Third, the model suggests that roughly 85 percent of households that resort to the bank are constrained. Thus, most households receive a lower credit amount because if the bank were to advance to them more capital, they would have the incentive to default.

\footnotetext{
${ }^{6}$ This point is also made in Braverman and Guasch (1986, 1993), Hoff and Stiglitz (1993), Besley (1994), Key (1997), and more generally in Banerjee (2003)

${ }^{7}$ See Chiappori and Salanié (2003) for a survey on empirical studies of contract theory, Key (1998) and Banerjee and Duflo (2003) for a review of the econometric issues in credit market studies.

${ }^{8}$ See Giné and Townsend (2004) for a welfare evaluation of the credit liberalization that took place in Thailand from 1975 to 1997.

${ }^{9}$ Using the same data set, Paulson and Townsend (2004) find evidence of credit constraints as wealth, even controlling for talent, contributes significantly to business start-ups.
} 
All these facts taken together indicate that the presence of enforcement problems, more than transaction costs, is crucial in explaining why formal credit is not accessible to everyone. Indeed, if we compare the estimated setup to the one without fixed transaction costs, average income would only increase by 0.1 percent, but if we compare it to the one with perfect enforcement, average income would increase by 25 percent. These numbers suggests that there is much to be gained from designing successful policy interventions.

To this end, we provide some evidence as to why credit subsidies in the form of a lower interest rate below the market level may not be an effective tool to combat poverty. First, banks are less willing to extend credit. Second, lower ability entrepreneurs are attracted, worsening the pool of loan applicants. The combination of these factors will lead to lower repayment rates, a fact that has been stressed in the literature. On the other hand, a land titling program would mitigate the enforcement problem and lead to an increase in formal credit. The ability of the loan applicant pool would not change, suggesting that repayment rates should not worsen.

The rest of the paper is organized as follows. Section 2 describes the model. Section 3 focuses on the core of the model given by a financial choice diagram. Section 4 presents the data used and describes its salient features. Section 5 turns to the maximum likelihood estimation of the underlying parameters of the model. Section 6 presents the estimation results and provides a quantitative assessment of government policies used in rural development. Finally, Section 7 concludes.

\section{The Model}

The model is static and deterministic. Agents are income maximizers and differ in wealth $b$, entrepreneurial ability $z$, and the type of project $(K, \eta)$ to be defined below. Thus, there are four sources of heterogeneity. Each entrepreneur decides how to finance the project by choosing to self-finance, resort to a formal or informal institution, or borrow from both sources. In addition, all agents can deposit their wealth in the formal institution or bank at no cost.

A formal credit institution, in this paper, is a profit maximizing intermediation entity that relies exclusively on the existing legal system to enforce contracts. In contrast, 
informal lenders may resort to other mechanisms. ${ }^{10}$ Informal lenders lend out of their own wealth and may resort to a formal institution for additional funds to re-lend, while formal institutions lend out of the collected deposits. The opportunity cost of funds is higher for the moneylender, however, because she can always deposit funds at the bank. Hence, there is a tradeoff between both sources of credit: while banks have access to a lower cost of funds, moneylenders can prevent their clients from "running away" with the borrowed capital.

The time-line of events is given in Figure 1. The enforcement problem is modelled by allowing bank clients to default on the contract by keeping the working capital before production takes place.

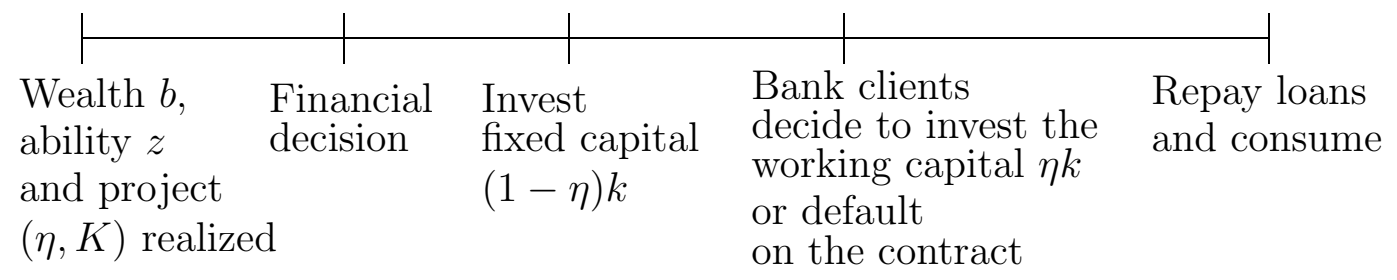

Figure 1: Time-line of the model

There is no uncertainty, so agents will simply seek to maximize end-of-period net income. Each entrepreneur has access to the following technology:

$$
f(z, k ; K, \eta)=z k+\tilde{\delta}(1-\eta) k, \quad \text { s.t. } \quad k \leq K,
$$

where $k$ denotes total capital invested and $K$ is the maximum scale at which each individual can operate. The term $\tilde{\delta}(1-\eta) k$ captures the value of the fixed capital once production has taken place. The parameter $\tilde{\delta}$ may be interpreted as the fraction of non-depreciated capital and $\eta$ denotes the fraction of working capital relative to total capital used in the production: if the ratio $\eta$ is one, only working capital is used and the project has no scrap value, whereas if the ratio $\eta$ is zero, all capital used is fixed

\footnotetext{
${ }^{10}$ The idea behind this assumption is that informal lenders can terminate a credit relationship or exert psychological pressure or harm their clients if they do not repay back their loans. Quoting Aryeetey (1997),

"To discourage default informal lenders go the homes of their clients to deliver verbal warnings."

Similarly, Aleem (1993) finds evidence of large switching costs between informal lenders, suggesting that reputation is important.
} 
and will remain after production has taken place. ${ }^{11}$ We can simplify notation by letting $\delta=\tilde{\delta}(1-\eta)$, where parameter $\delta$ is now individual specific through the dependency on $\eta$.

Throughout the paper, we define a constrained household as the one that invests a level of capital below its maximum capacity, so that $k<K$. Similarly, an unconstrained household invests the full amount $k=K$.

We now proceed to compute the net income obtained from each financial choice. Net income $Y$ depends explicitly on the household ability $z$, wealth $b$ and the type of project $(K, \eta)$. It is also subscripted by the financial choice: self-finance $(\mathrm{S})$, bank $(\mathrm{B})$, moneylender $(\mathrm{M})$, and bank and moneylender $(\mathrm{BM})$.

If the entrepreneur decides to self-finance $(\mathrm{S})$, she will obtain a net income of

$$
\begin{array}{r}
Y_{S}(z, b ; K, \eta)=\max _{k} z k+\delta k+(b-k) r_{D} \\
\text { s.t. } \quad k \leq b, \quad k \leq K .
\end{array}
$$

where $r_{D}$ denotes the interest rate on deposits. Since the technology is linear, we can write the optimal choice of capital as

$$
k_{S}(z ; K, \eta)=\left\{\begin{array}{l}
K \quad \text { if } z \geq r_{D}-\delta \text { and } b \geq K, \\
b \quad \text { if } z \geq r_{D}-\delta \text { and } b<K, \\
0 \quad \text { if } z<r_{D}-\delta .
\end{array}\right.
$$

In words, she will invest $K$ if it is profitable and she has enough wealth, will invest her total wealth $b$ if the maximum scale $K$ is larger than her wealth, and will not invest at all if the return on the investment is lower than the interest the bank pays for deposits.

If she goes to the bank (B), her net income can be written as

$$
\begin{aligned}
Y_{B}(z, b ; K, \eta)=\max _{k} z k-l_{B} r_{B}+\left(b-k+l_{B}\right) r_{D}+\delta k-\Gamma_{B} \\
\text { s.t. } \quad k \leq K \text { and } \\
\quad z k-l_{B} r_{B}+\left(b-k+l_{B}\right) r_{D}+\delta k \geq \eta k .
\end{aligned}
$$

\footnotetext{
${ }^{11}$ In other words, capital $k$ is the sum of fixed capital $k^{F}$ and working capital $k^{W}$. Then, $\eta=\frac{k^{W}}{k^{W}+k^{F}}$.
} 
The interest rate $r_{B}$ denotes the cost of borrowing and the parameter $\Gamma_{B}$ captures the fixed transaction cost of dealing with a bank. This cost parameter captures all expenses related to obtaining the loan: trips to the bank, bank fees and due diligence to assess the repayment capacity of the borrower. By having the borrower pay $\Gamma_{B}$, the bank learns the borrower's characteristics $(z, b, K, \eta)$. The last constraint captures the enforcement disadvantage that banks face. Before producing, bank clients can "run away" with the working capital advanced, at the cost of losing all their deposited wealth as well as the fixed capital scrap value, which will be seized by the bank. Implicitly, we assume that although banks may fully observe their borrowers' actions, they have no legal mechanisms to prevent a borrower from "consuming" the working capital.

Also implicit in the agent's problem stated in (4) is the notion that banks are competitive and will, therefore, offer contracts that maximize their clients' income. The agent will borrow an amount $l_{B}=k-b$, (i.e. the difference between total capital invested $k$ and wealth $b$ ), so we can rewrite the agent's net income in (4) as:

$$
\begin{aligned}
Y_{B}(z, b ; K, \eta)=\max _{k} z k & -(k-b) r_{B}+\delta k-\Gamma_{B} \\
\text { s.t. } \quad k \leq K \text { and } & \\
& z k-(k-b) r_{B}+\delta k \geq \eta k .
\end{aligned}
$$

The optimal choice of capital for the entrepreneur depends on whether or not the enforcement constraint is binding. If it binds, the maximum amount of capital that the bank is willing to lend is given by:

$$
k^{c}=\frac{b r_{B}}{\eta-\left(z+\delta-r_{B}\right)} .
$$

The above expression is found using the enforcement constraint at equality and solving for $k$. Notice that there will be less constraints if the project is more productive (ability $z$ is high), the entrepreneur is richer, or she operates a technology with relatively more fixed assets (lower $\eta){ }^{12}$

If the constraint does not bind, the entrepreneur earns net income $Y_{B u}=(z+\delta-$ $\left.r_{B}\right) K+r_{B} b-\Gamma_{B}$, while if it binds, she earns $Y_{B c}=\eta k^{c}-\Gamma_{B}$.

\footnotetext{
${ }^{12}$ The expression in (6) written as $k^{c} \equiv \lambda(z, \eta) b$ can be seen as a generalization of the parameter $\lambda$ in Evans and Jovanovic (1989). In their paper, $\lambda$ measures the amount that can be borrowed from a bank as a proportion of wealth. Here, as in Banerjee (2003), it depends explicitly on the agent's characteristics.
} 


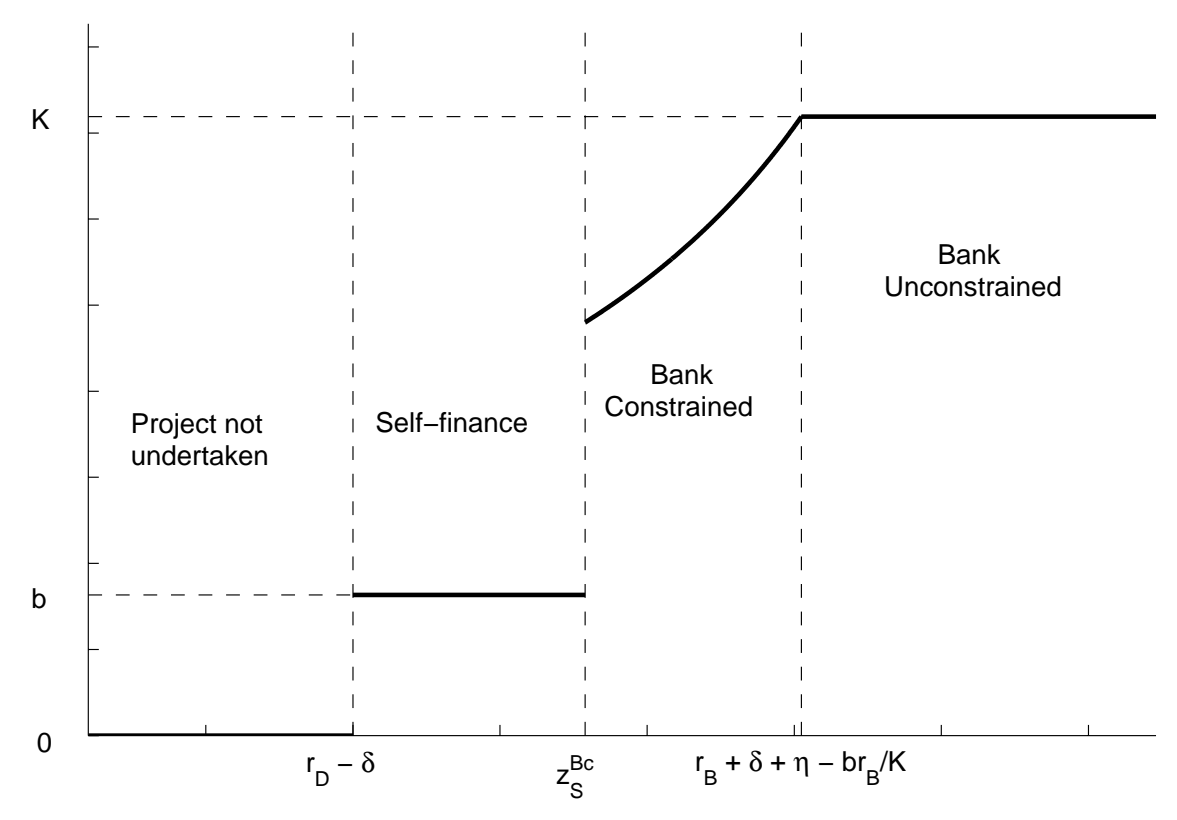

Figure 2: Optimal investment $k$

Figure 2 plots the optimal investment $k$ as a function of ability $z$. When the return on the investment $z+\delta$ is lower than the deposit rate $r_{D}$, it pays to keep the money in the bank. When ability is higher than the cutoff $r_{D}-\delta$ but lower than some level $z_{S}^{B c}$, the agent self-finances investing her total wealth. The cutoff ability $z_{S}^{B c}$ is found by equating the net incomes from self-financing and that of resorting to a bank but being constrained. The capital invested is larger than wealth $b$ because the fixed cost $\Gamma_{B}$ of transacting with the bank must be foregone. Notice also that, in this segment, investment is an increasing function of ability $z$ until the capacity constraint $K$ is reached. For higher ability values, the agent will be unconstrained.

Now suppose that the agent resorts to a moneylender. The amount borrowed is $l_{M}=k-b$ and her net income becomes:

$$
\begin{aligned}
Y_{M}(z, b ; K, \eta)= & \max _{k} z k-(k-b) r_{M}+\delta k-\Gamma_{M} \\
\text { s.t. } \quad k \leq K &
\end{aligned}
$$

where $r_{M}$ denotes the interest rate charged by the moneylender and it is assumed that $r_{M}>r_{B}$. The moneylender is not subject to enforcement problems and will therefore 
advance $l_{M}=K-b$ so that the the entrepreneur operates the project at maximum capacity. ${ }^{13}$

Finally, the entrepreneur may find it in her interest to resort to both a bank and a moneylender (BM). This case will arise if the bank offers too little capital due to enforcement problems: the project may be intensive in working capital (high $\eta$ ) or the entrepreneur may not be talented enough to convince the bank that she will not default on the loan contract and run away with the working capital. Since the interest rate charged by the moneylender is higher than that of the bank, the agent borrows from the bank as much as the bank is willing to lend her $l_{B}=k^{c}-b$ and will then turn to the moneylender to finance $l_{M}=K-k^{c}$, the remaining capital requirement. ${ }^{14}$

Net income can be written as total revenues from investing the maximum scale $(z+\delta) K$ minus loan repayments and fixed costs. More formally,

$$
\begin{aligned}
Y_{B M}(z, b ; K, \eta) & =z K-\left(k^{c}-b\right) r_{B}-\left(K-k^{c}\right) r_{M}+\delta K-\Gamma_{B}-\Gamma_{M} \text { or } \\
Y_{B M}(z, b ; K, \eta) & =Y_{M}(z, b ; K, \eta)+\left(k^{c}-b\right)\left(r_{M}-r_{B}\right)-\Gamma_{B} \\
& =Y_{B c}(z, b ; K, \eta)+\left(K-k^{c}\right)\left(z+\delta-r_{M}\right)-\Gamma_{M}
\end{aligned}
$$

where $Y_{B c}(z, b ; K, \eta)$ denotes net earnings from dealing with the bank when capital is constrained.

In sum, the model posits that an entrepreneur with wealth $b$ and fraction of working to total capital $\eta$, facing interest rates $r_{B}, r_{M}$ and fixed costs $\Gamma_{B}, \Gamma_{M}$, will decide how to finance her project based on her maximum scale $K$ and entrepreneurial ability $z$, by choosing the lender that offers the credit contract yielding the highest net income. In the next section, we construct a diagram that explains this financing choice given the entrepreneur and project characteristics.

\footnotetext{
${ }^{13}$ The problem in (7) assumes that moneylenders behave competitively. As mentioned in Banerjee (2003), Aleem (1989) and other studies present evidence suggesting that informal lenders earn on average relatively low profit margins, a finding consistent with competition.

${ }^{14}$ Bell et al. (1997) provide direct evidence of this sequential structure in which households first approach a formal institution and then resort to informal sources for additional funds.
} 


\section{The Financial Choice Diagram}

The goal is to construct a diagram that determines the optimal financial choice for any point in the ability-scale space $(z, K)$. This space is chosen because ability $z$ and scale $K$ are unobserved. The observed variables such as wealth $b$, the fraction $\eta$, interest rates and transaction costs are fixed in the background and determine the curves in the diagram. The idea is simply to obtain cutoff scale values $K$ as a function of ability $z$ that leave an agent indifferent between any two lending choices. The notation for all critical cutoff scales in Figure 3 except for $K^{E C}(z)$ is such that $K_{S}^{M}(z)$, say, is found by equating net incomes $Y_{S}=Y_{M}$. The cutoff scale $K^{E C}(z)$ is simply Equation 6 . These critical levels depend on the variables $(b, \eta)$ and parameters $\left(r_{B}, r_{M}, \Gamma_{B}, \Gamma_{M}\right) .{ }^{15}$ For example, if the fixed cost of accessing the bank $\Gamma_{B}$ declines, the cutoff curves will move enlarging the region where the agent is better off resorting to the bank. In fact, as stated in Proposition 1 below, some regions that appear in Figure 3 do not exist for certain combinations of variables and parameters. We now provide some intuition why these regions arise where they do, while Appendix B shows how these different cutoff curves are obtained analytically.

Region S (Self-Finance): If the agent has a scale $K$ below $K_{S}^{M}(z)$ or $K_{S}^{B u}(z)$, she will self-finance (Region $\mathbf{S}$ ). For a given capacity constraint $K$, the higher the entrepreneur's ability $z$, the more likely she is to look for outside funds. Intuitively, if the entrepreneur is not very talented, it doesn't pay to incur the fixed costs and interest rates in order to expand capacity.

Region M (Moneylender only): When the entrepreneur decides to finance the project externally, Region $\mathbf{M}$ becomes relevant if the scale $K$ is lower than $K_{M}^{B u}(z)$ or higher than $K_{B c}^{M}(z)$. In the first case, the amount of credit needed is small (the scale $K$ is close to wealth $b$ ) and so saving on bank interest payment does not compensate its higher fixed cost. In the latter case, since wealth $b$ is fixed in Figure 3, the amount of credit needed (loan size) increases with capacity constraint $K$. However, given her relatively low ability $z$, the bank is not willing to advance enough capital to make savings on interest payment worthwhile, and so the entrepreneur is better off resorting to the moneylender only.

\footnotetext{
${ }^{15}$ Figure 3 is drawn assuming that $\Gamma_{B}>\Gamma_{M}$ and $r_{M}>r_{B}$ as supported by the data.
} 


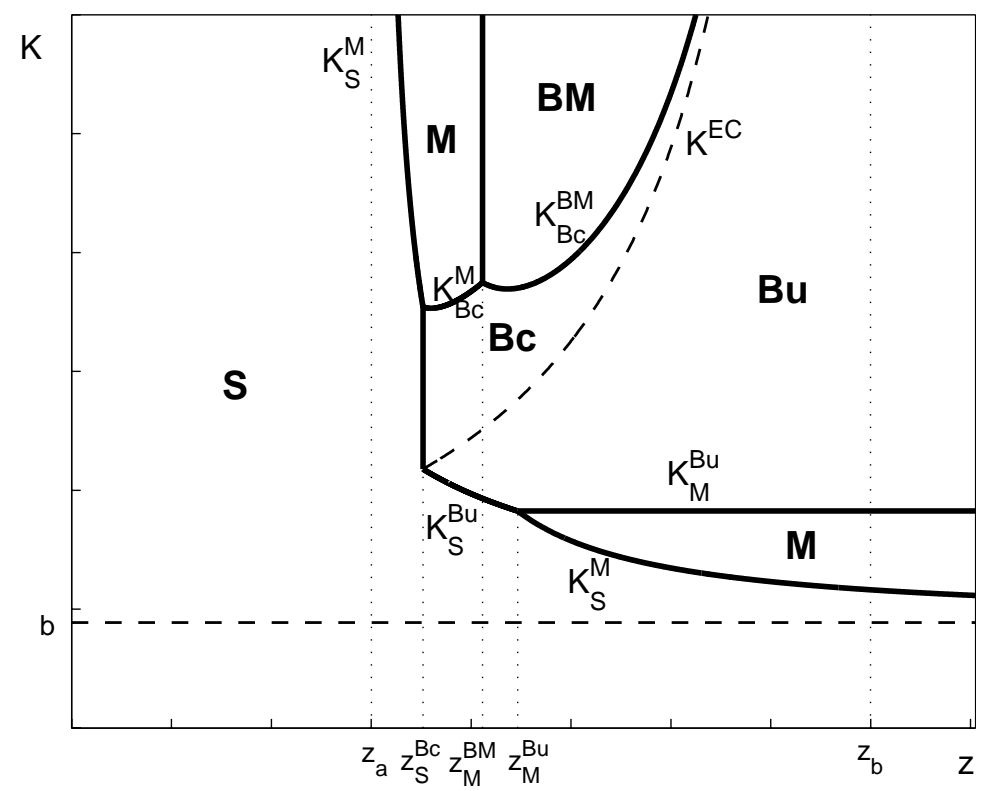

Figure 3: Financial Choice Map

The solid thick lines mark the different financial choices, S,M,B,BM. The horizontal dashed line indicates the level of wealth $b$. The cutoff values of ability $z$ displayed are defined in Appendix B.

Region BM (Bank and Moneylender): If the scale $K$ is higher than the cutoff $K_{B c}^{B M}(z)$, she will resort to both a bank and a moneylender (Region BM). The constrained amount $k^{c}$ that a bank is willing to lend is increasing in ability $z$ (see Equation $6)$. Thus, for a given ability-scale pair $(z, K)$ in the upper Region $\mathbf{M}$, if we fix the scale $K$ and increase the ability $z$, we reach a point where the entrepreneur will find it profitable to incur the fixed cost $\Gamma_{B}$ and reduce total interest payment by borrowing less from the moneylender.

Region Bc and Bu (Bank only, Constrained and Unconstrained): If the scale $K$ falls between the cutoffs $K_{M}^{B u}(z)$ and $K^{E C}(z)$, she will borrow from a bank and be unconstrained (Region Bu), earning income $Y_{B u}$, whereas if it falls between the cutoffs $K^{E C}(z)$ and $K_{B c}^{M}(z)$ or $K_{B c}^{B M}(z)$, she will still borrow from a bank but be constrained (Region Bc) and earn income $Y_{B c}$. For low ability levels, the bank will limit the amount of lending because the entrepreneur is tempted to "run away" with the working capital if she was granted the maximum capacity $K$. 
The following proposition describes the conditions that the variables $(b, \eta)$ and parameters $\left(r_{B}, r_{M}, \Gamma_{B}, \Gamma_{M}\right)$ must satisfy to generate a particular finance map. The proof is relegated to Appendix B.1.

Proposition 1. There exist wealth levels $\hat{b}$ and $\tilde{b}, \hat{b}<\tilde{b}$ such that:

i) If $0 \leq b<\hat{b}$ then wealth $b$ is so low that the separate regions $\mathbf{M}$ in Figure 3 merge together.

ii) If $\hat{b} \leq b<\tilde{b}$ and $\eta>r_{M}-r_{B}$ we obtain Figure 3 .

iii) If $b \geq \tilde{b}$ and $\eta>r_{M}-r_{B}$, the top region $\mathbf{M}$ disappears because wealth $b$ is so high enough that even though the agent is constrained, the bank will advance enough capital to make going to the moneylender alone never optimal.

iv) If $\eta<r_{M}-r_{B}$ the ratio of working to total capital $\eta$ is so low that banks have no problem in advancing funds. The top region $\mathbf{M}$ and the region $\mathbf{B M}$ disappear.

In order to explain the financial choices observed in the data, both elements of the model -limited enforceability and transaction costs- are needed. To see this, the left panel of Figure 4 was constructed using the parameter values of Figure 3 but setting the fixed costs $\Gamma_{B}=\Gamma_{M}=0$. In the absence of transaction costs, all agents that require financing first borrow from the bank, and only those that are constrained also borrow from the moneylender. Thus, Region $\mathbf{M}$ disappears as it never pays to resort only to the moneylender. Consider now a situation where banks are able to enforce credit contracts perfectly. Since now banks advance funds up to the maximum scale $K$, the choice between bank and moneylender is driven solely by the magnitude of the fixed costs and the loan size. In this scenario, Region BM disappears because the entrepreneur is never constrained. This is shown in right panel of Figure 4, still drawn using the parameter values of Figure 3.

Since the data report household in each of the four financial choices, namely $\mathbf{S}, \mathbf{B}$, $\mathbf{M}$ and $\mathbf{B M}$, both elements of the model are relevant.

Clearly, for a given entrepreneur and financial choice, one feature, say the cost of accessing formal credit, may be more relevant than another. Thus the diagram faced by this household will differ from that of another household. The point is that some regions are relevant for certain households and thus the model must be flexible to accommodate them. The spirit of the estimation in Section 5 is precisely to search over fixed costs and 

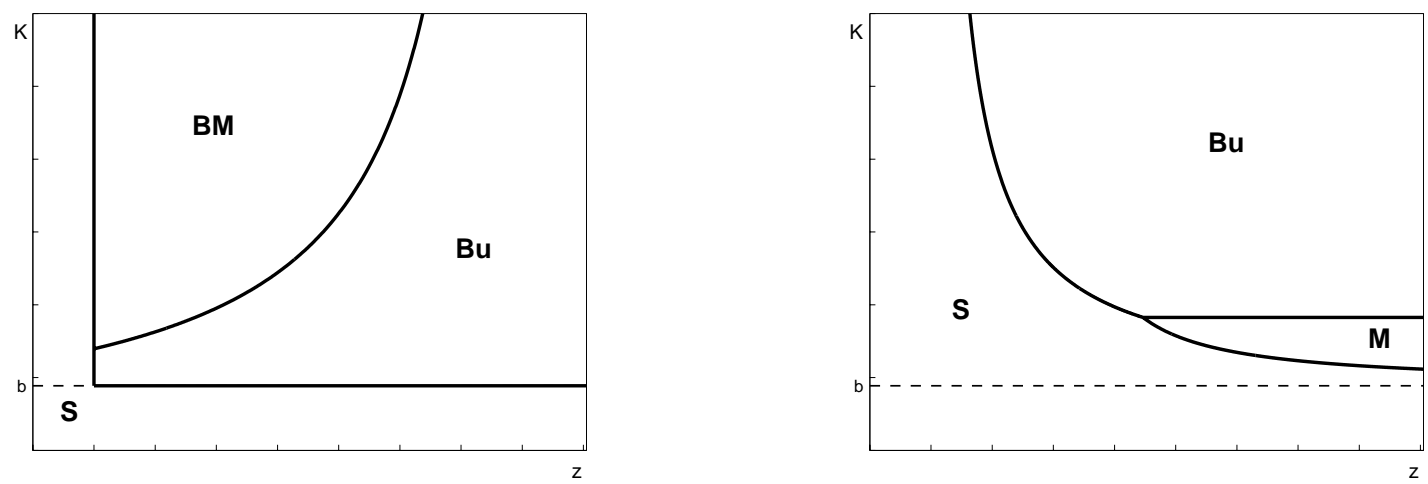

Figure 4: Financial Choice without transaction costs (left) or perfect enforcement (right).

other parameters so as to maximize the likelihood that a household obtains the reported expected net income from its financial choice in the particular diagram it faces.

\section{The Data}

The data used in this paper are the Townsend-Thai data set and come from a specialized but substantial cross sectional survey conducted in two provinces in the Northeast and two in the Central region of Thailand in May 1997. It contains a wealth of precrisis socio-economic and financial data on 2,612 households. ${ }^{16}$ The survey instruments collected current and retrospective information on wealth (household, agricultural, business and financial) and access and use of a wide variety of formal and informal financial institutions (commercial banks, agricultural banks, village lending institutions, moneylenders, as well as friends, family and business associates). The data also provide detailed information on household demographics, education and other characteristics.

Because these data provide rich and detailed information about the household and the financial intermediaries, they are particularly well suited for the present study. Appendix A describes how the variables are constructed from the original data. We now turn to a brief description of some of the salient features of the data and constructed variables.

\footnotetext{
${ }^{16}$ See Townsend et al. (1997) for more details on the sampling methodology and the data. From the original data of 2,880 households we dropped those did not report expected income.
} 


\subsection{Features of the Data}

The survey reveals that households are very active in the credit market as roughly half of the sample has between one and two loans and only about a third of the households have no outstanding loans.

Table 1 displays the characteristics of loans given by different lenders. The formal sector, especially through the Banc for Agriculture and Agricultural Cooperatives (BAAC), does the bulk of the lending accounting for 69 percent of the total volume of lending ${ }^{17}$. BAAC loans, which alone lends out 36.5 percent of volume, are divided into individual loans, which are backed by collateral, and group loans, which only require guarantors. When we consider the number of loans, the formal sector still dominates the informal giving out 59 percent of the total number of loans. ${ }^{18}$ Although the standard deviations are also high, the hypothesis that the average amounts are equal across different sources of lending can be rejected at a 5 percent significance level.

The average length of the loans is surprisingly high, especially if compared with the findings of Aryeetey (1997). He reports an average maturity of loans from moneylenders of 3 months, although he finds that the practice of rolling over short-term debt is widespread. The large standard deviation in the duration of the loans suggests sizable disparities in the maturities. The median length is 47 months for loans from commercial banks and 12 months for the rest of formal and informal institutions.

Table 1 also reports two net interest rates, $r$, computed using all loans and $r_{c}$, computed only using loans bearing a positive interest rate. As expected, informal lenders tend to charge a higher interest rate. Among formal loans, it is the institutions which require collateral that charge lower interest rates. Given that these institutions tend to disburse larger amounts, this may reflect lower costs of funds or lower intermediation costs. We also report the fraction of loans that required collateral. As expected, loans from commercial banks and, by construction, individual BAAC loans, are mostly backed by assets.

\footnotetext{
${ }^{17}$ The BAAC is a government development bank and a major credit institution in the rural areas of Thailand. Since 1977, the BAAC has been providing loans to farmers with collateral requirements for loans exceeding US $\$ 2,400$, loans to farmer groups through agricultural cooperatives and saving services.

${ }^{18}$ This significant presence of the formal sector is in contrast with the findings of Udry (1993) and Aryeetey (1997) in rural Africa, where formal credit remains small.
} 
Table 1: Loan Characteristics by lender

\begin{tabular}{lrrrcccrr}
\hline & Obs. & $L$ & $\sigma(L)$ & Maturity & $r$ & $r_{c}$ & Collat. & Z. Int. \\
\hline Com. Bank & 118 & 196 & 246 & 54 & 0.2208 & 0.2326 & 83.1 & 5.1 \\
BAAC & 1,293 & 41 & 80 & 20 & 0.2232 & 0.2239 & 29.4 & 0.3 \\
$\quad$ Individual & 380 & 75 & 130 & 30 & 0.1273 & 0.1273 & 100.0 & 0.0 \\
$\quad$ Group & 913 & 27 & 37 & 16 & 0.2631 & 0.2643 & 0.0 & 0.5 \\
Ag. Coop & 353 & 43 & 69 & 18 & 0.1373 & 0.1385 & 36.3 & 0.9 \\
Vil. Inst. & 174 & 47 & 103 & 32 & 0.1036 & 0.1639 & 9.2 & 36.8 \\
Informal $P$ & 553 & 51 & 157 & 21 & 0.4203 & 0.5176 & 20.1 & 18.8 \\
Informal $R$ & 820 & 20 & 44 & 17 & 0.2736 & 0.5499 & 4.9 & 50.2 \\
\hline Formal & $\mathbf{1 , 9 2 8}$ & $\mathbf{5 1}$ & $\mathbf{1 0 6}$ & $\mathbf{2 3}$ & $\mathbf{0 . 1 9 4 8}$ & $\mathbf{0 . 2 0 4 1}$ & $\mathbf{3 1 . 9}$ & $\mathbf{4 . 6}$ \\
Informal & $\mathbf{1 , 3 7 3}$ & $\mathbf{3 3}$ & $\mathbf{1 0 6}$ & $\mathbf{1 8}$ & $\mathbf{0 . 3 3 2 7}$ & $\mathbf{0 . 5 3 3}$ & $\mathbf{1 1 . 0}$ & $\mathbf{3 7 . 6}$ \\
\hline \hline
\end{tabular}

Note: Each loan is counted as an observation. Com. Bank includes Finance and Insurance Companies. Village-level Institutions include loans from Village Funds, Rice Banks, Buffalo Banks and Production and Credit Groups. "Informal P" includes Moneylenders, Store Owners, Landlords and traders. "Informal R" includes friends and relatives. Column $L$ reports the average loan size and column $\sigma(L)$ its standard deviation in 1,000 Baht. The figures in both columns are in Baht. The length of the loan is in months. The interest rates $r$ and $r_{c}$ are net and yearly compounded. Column "Collat." reports the percentage of loans that required collateral. Finally, column "Z. Int." reports the percentage of loans given interest-free.

Source: Townsend-Thai data.

Table 2 reports the variables by source of credit that will be used in the estimation. From the sample of 2,612 households, 34 percent of the sample self-finance, 36 percent borrow from a formal institution, 17 percent borrow from an informal lender only and 13 percent of the sample borrow from both a formal and an informal lender. These numbers are large if compared to those of Aryeetey (1997) where only 16 percent of all households interviewed in the Ghana Living Standards Measurement Survey reported borrowing from the formal sector.

Observed loan size $k-b$ is large for clients of a formal institution that requires collateral and for those households who resort to both a formal and informal lender. This fits well with the prediction of the model that institutions with higher fixed costs should cater to households with higher financing requirements. A test of equal mean capital requirements across lending choices that is easily rejected by the data.

Those who borrow from a formal institution are also wealthier than those who borrow from an informal source or both sources. Those who self-finance are, on average, 
Table 2: Summary of Model Variables

\begin{tabular}{lrrrrr}
\hline & Own & Formal C & Formal NC & Informal & Both \\
\hline $\begin{array}{l}\text { Loan size } \\
\quad \text { Mean }\end{array}$ & - & 125 & 37 & 35 & 126 \\
$\quad$ Std. Dev. & & 297 & 57 & 98 & 257 \\
Wealth & 1,715 & 1,952 & 1,207 & 982 & 1,182 \\
$\quad$ Mean & 6,116 & 6,014 & 4,495 & 4,223 & 5,087 \\
$\quad$ Std. Dev. & & & & & \\
Expected Income & 1,946 & 2,311 & 1,440 & 1,198 & 1,459 \\
$\quad$ Mean & 6,319 & 6,417 & 4,745 & 4,386 & 5,423 \\
$\quad$ Std. Dev. & & & & & \\
Working to Total Capital ratio & 0.649 & 0.513 & 0.706 & 0.747 & 0.684 \\
mean & 0.331 & 0.318 & 0.320 & 0.298 & 0.329 \\
Std. Dev. & & & & & \\
Credit Constraints & 0.380 & 0.563 & 0.668 & 0.517 & 0.652 \\
mean & 0.486 & 0.497 & 0.471 & 0.500 & 0.477 \\
Std. Dev. & & & & & \\
Mean Household Characteristics & & & & & \\
Years of education & 3.877 & 4.217 & 4.377 & 3.797 & 4.440 \\
Head of Household is Male & 0.694 & 0.791 & 0.852 & 0.775 & 0.831 \\
Past client of formal inst. & 0.457 & 0.802 & 0.787 & 0.523 & 0.712 \\
Past client of informal inst. & 0.155 & 0.203 & 0.226 & 0.229 & 0.215 \\
Formal inst. present in village & 0.278 & 0.783 & 0.759 & 0.443 & 0.762 \\
Number of formal inst. in village & 0.540 & 1.534 & 1.516 & 0.888 & 1.583 \\
Savings in formal institution & 0.510 & 0.814 & 0.834 & 0.329 & 0.800 \\
Member of a village committee & 0.056 & 0.121 & 0.140 & 0.074 & 0.119 \\
$\quad$ & & & & & \\
Observations & 880 & 446 & 494 & 447 & 345 \\
\hline \hline
\end{tabular}

Note: The category "Own" includes households who do not have outstanding loans. "Formal C" includes institutions that require collateral: Commercial Banks, Finance and Insurance Companies and BAAC individual loans. "Formal NC" includes BAAC group loans, loans from Agricultural Cooperatives and loans from village-level institutions. "Informal P" and "Informal R" are merged into Informal. "Both" include households who actively borrowed from both formal and informal sources. Capital requirements, wealth and income figures are in 1,000 Baht.

Source: Townsend-Thai Data.

wealthier than informal borrowers but the high standard deviation suggests that there is more dispersion. The model can also rationalize these facts. Holding the ratio $\eta$ and ability $z$ constant, wealthier households will rely on formal institutions for additional 
funds because they are in a better position to put up collateral. In addition, wealthy households that decide to self-finance can be interpreted as having a low scale project or not being very talented (low $z$ ). The top panels of Figure 5 complements Table 2 by displaying the distribution of the $\log$ of wealth $b$ and loan size $k-b$.
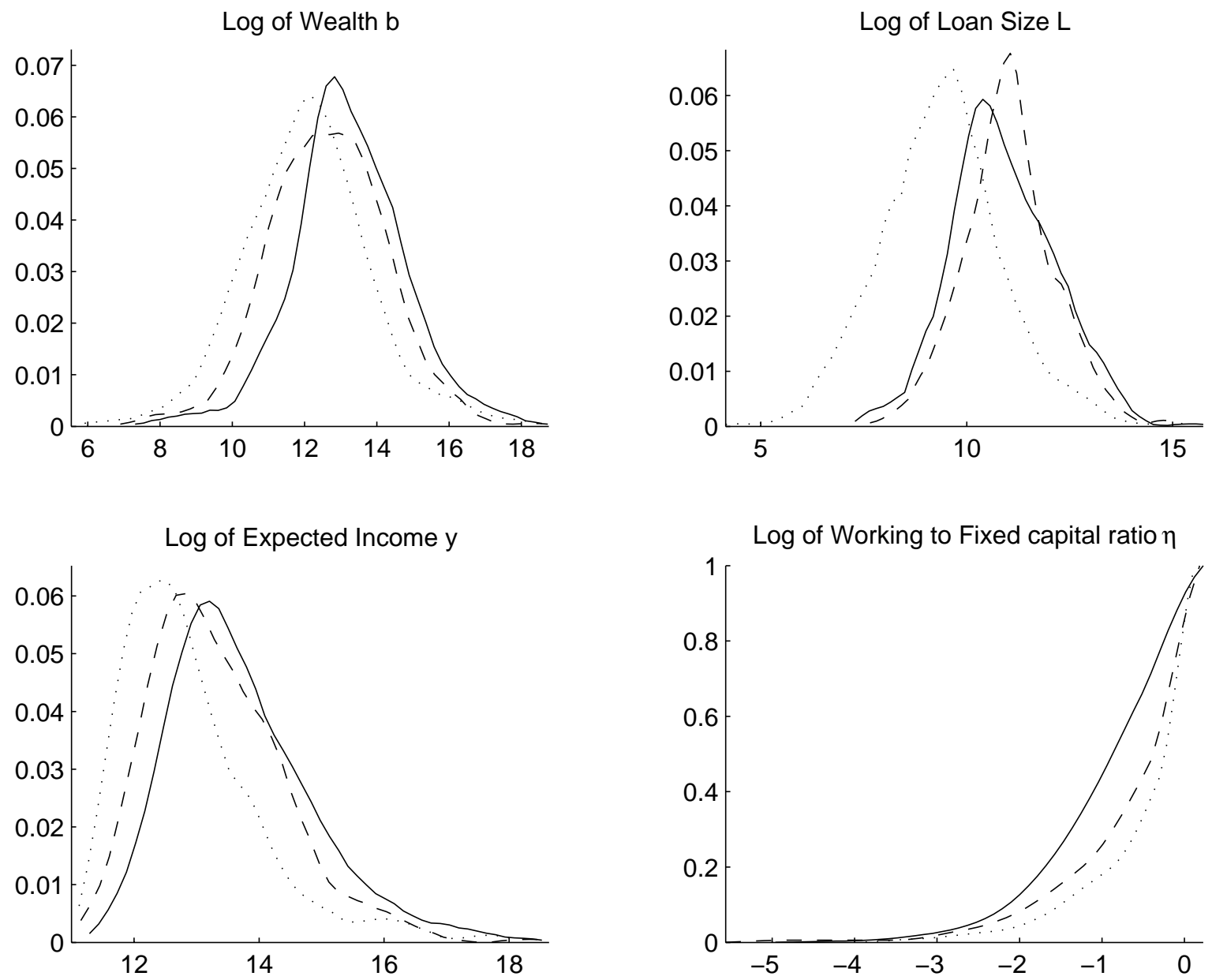

Figure 5: Kernel Density Estimations

Legend: Formal C “-", Informal "..." Both ". -".

Table 2 and the lower panels of Figure 5 report the average working to total capital ratio $\eta$ and the constructed measure of expected income $y$. The lower right panel of Figure 5 plots the cumulative distribution of the $\log$ of ratio $\eta$. Indeed, the mean ratio $\eta$ behaves as the model predicts, a fact also documented by Feder et al. (1988) and Feder (1993). Clients of banks that require collateral have the lowest average ratio $\eta$, households that borrow from both have on average a higher ratio, whereas those who 
borrow from informal lenders only have the highest ratio. Despite the large standard deviation, the hypothesis of equal means across borrowing choices is rejected at all significance levels.

The lower left panel shows the distribution of log expected income $y$. Together with the top panels, one can estimate the profitability in each lending choice. It seems that "Informal" has higher profitability on average than "Both" or "Formal C". The model can explain the relatively high profitability of informal borrowers as they operate at a small scale and decide not to incur the fixed cost of formal finance.

Finally, Table 2 shows the fraction of households that report being credit constrained. ${ }^{19}$ Again, a test of equal means is rejected at all significance level. Households which borrow exclusively form the formal sector and those which are forced to resort to both sources are more likely to be credit constrained, which as the model suggests, are the two lending choices in which households are more likely to be credit constrained.

Finally, Table 2 reports several household characteristics that could affect the fixed costs $\Gamma_{B}, \Gamma_{M}$ and the value of default on a bank contract $v=\eta k^{c}$.

Following Guiso, Sapienza and Zingales (2004), among others, we consider measures of the household social capital and its ties with their lenders. We proxy for social capital using data on household membership in the village committee. Membership may capture social characteristics such as sense of duty, trustworthiness and popularity among fellow villagers. ${ }^{20}$

We use several measures that characterize the ties that households have with the different lenders. First, we record whether the household has previously borrowed from the lender. If the borrower is an old client, the lender will have more accurate information and will be keen on extending credit and possibly on lowering the cost of capital. ${ }^{21}$

\footnotetext{
${ }^{19}$ Households were specifically asked the following question in the survey:

If you could increase the size of your enterprise, do you think it would be more profitable?

If a household responded affirmatively to the question it is considered credit constrained.

${ }^{20}$ For our purposes, being respected and well-known in the community may result in greater access to funds. However, in the case where membership in these committees grants power to divert funds for private, non-productive purposes, then membership may be correlated with greater risk of default on the bank loan and if so we would expect members to face the enforcement constraint more often.

${ }^{21}$ The observed correlation between past and current borrowing from a particular borrower can be explained by two distinct scenarios. First, as a consequence of having borrowed in the past, the cost of accessing the lender is now lower and thus it is more likely that the household will borrow again. However, some unobserved characteristic inherent to the household may place him in a better position
} 
Second, we measure the strength of the relationship by looking at whether households have savings deposits with a formal institution. The argument here is that these nonloan services can be used by the creditor to monitor the household or obtain additional information thereby reducing the expected cost of such loans.

\section{Estimation of the Model}

We consider two different specifications of the fixed costs and the value of default. First, each household faces the same fixed costs $\Gamma_{B}$ and $\Gamma_{M}$, and is subject to the same enforcement. Alternatively we allow these fixed costs to vary among households. In particular, we assume that $\Gamma_{B i}=\exp \left(x_{B i} / \gamma_{B}\right)$ and $\Gamma_{M i}=\exp \left(x_{M i} / \gamma_{M}\right)$, where $x_{j i}$ is the column vector of characteristics of household $i$ relevant to the fixed $\operatorname{cost} \Gamma_{j}$. Thus far, all the observed heterogeneity is captured in the fixed cost of external finance. However, it is possible that households differ in their ability to use the working capital for their private benefit. In this case, the value of defaulting on a bank contract would be householdspecific. More formally, we can write this value as $v\left(x_{\eta}\right)=\exp \left(x_{\eta i} / \gamma_{\eta}\right) \eta k$ where, again, $x_{\eta i}$ is the column vector of characteristics of household $i$ relevant for the value of default $v$.

We now derive the likelihood dictated by the model. Since ability $z$ and the maximum scale $K$ are not observable, this likelihood can be determined entirely from the cutoff curves $K_{j}^{i}, i, j=\{S, B, M, B M\}$ in the maps described in Proposition 1, Equations 2, 5, 7 and 8 in Section 2 describing the net income from each financial choice and the joint distribution of ability $z$ and scale $K$.

We assume that the log of ability $z$ and the log of maximum scale $K$ follow a bivariate normal distribution

$$
(\zeta, \kappa) \sim B V N\left(\mu_{\zeta}, \mu_{\kappa}, \sigma_{\zeta}^{2}, \sigma_{\kappa}^{2}, \rho\right)
$$

where $\zeta=\log (z-\underline{z})$ and $\kappa=\log (K)$. Notice that ability has a lower bound at $\underline{z}=r_{D}-\delta$ because it has to be worthwhile to undertake the investment. Now let

to borrow, say because a relative is a credit officer in the formal institution. Since this unobserved characteristic is correlated through time, it may appear that having borrowed in the past is a good predictor for current behavior when in fact it just happens to be a good proxy for the unobserved characteristic which is responsible for the observed behavior. This so-called "state dependence" problem is pointed out by Heckman (1981). We therefore instrument past membership using how long formal institutions have been in the village. 
$\theta=\left(\gamma_{B}, \gamma_{M}, \mu_{\zeta}, \mu_{\kappa}, \sigma_{\zeta}, \sigma_{\kappa}, \rho\right)$ denote the vector of parameters of the model and let $\nu_{i}=\left(b_{i}, \eta_{i}, x_{B i}, x_{M i}, x_{\eta i}\right)$ denote the vector of variables. ${ }^{22}$ Suppose we have a sample of $n$ households and let $l_{i}=\{S, B, M, B M\}$ denote the financial decision taken and $y_{i}$ the income derived from that choice. Then, letting the likelihood $f\left(l_{i}, y_{i} \mid \nu_{i}, \theta\right)$ that a household with characteristics $\nu_{i}$ facing parameters $\theta$ will choose $l_{i}$ and derive net income $y_{i}$, we can write the likelihood function ${ }^{23}$ as

$$
L_{n}(\theta)=\sum_{i=1}^{n} f\left(y_{i}, l_{i} \mid \nu_{i}, \theta\right)
$$

which can be maximized numerically using a standard maximization routine. ${ }^{24}$

\subsection{Estimation Issues}

The model imposes certain preliminary restrictions on the data. First, wealth should be positive, so we drop all households that report zero wealth. This amounts to 9.13 percent of the original sample. Second, according to Proposition 1.iv) the model assigns zero probability to households that report borrowing from both sources with $\eta<r_{M}-r_{B}$. These only account for 0.52 percent of the sample. Finally, 6.11 percent of the sample is also dropped because the constructed income is too low for the model to rationalize the choice of lender. ${ }^{25}$

The estimation requires prices $r_{B}$ and $r_{M}$. Given the geographical dispersion in interest rates, we use the sample village-level net interest rate charged by formal and informal lenders respectively. ${ }^{26}$ Notice then that the cost of capital is taken to be uniform within a given village. While formal institutions do have rigid rules for setting the interest rate, informal lenders could in principle tailor them to borrower characteristics.

\footnotetext{
${ }^{22}$ The parameter $\tilde{\delta}$ cannot be estimated because there is too little variation in $\delta$ to estimate it separately from the mean of ability $z$. Intuitively, the assumed linearity of the technology allows only estimation of the gross return $z+\delta$. Essentially then only one constant is identified and we therefore fix $\tilde{\delta}=1$.

${ }^{23}$ The Appendix derives explicitly the form of the likelihood $f\left(y_{i}, l_{i} \mid \nu_{i}, \theta\right)$.

${ }^{24}$ In particular, we used the MATLAB routine fmincon starting from a variety of predetermined guesses.

${ }^{25}$ The model assigns zero probability to households that $l_{i}=B$ and $y_{i}<r_{B} b$ and $l_{i}=M$ or $l_{i}=B M$ and $y_{i}<r_{M} b$.

${ }^{26}$ The expected inflation rate in Thailand was around 4 percent in 1997 . After trying different geographical units, the village was chosen because it was the only unit where the dispersion in the interest rates within a unit were significantly lower than across units.
} 
Informal interest rates, as Banerjee (2003) suggests, can be decomposed into default rate, opportunity cost, monitoring cost and monopoly rents. In the model here, there is no default and no monopoly rents as moneylenders are assumed competitive, thus informal interest rates are determined by monitoring and opportunity costs. Given the low dispersion found in the reported informal interest rates within a village, the data suggests that both monitoring and opportunity costs are village specific.

\section{Results}

We combine each "cost" with each "enforcement" specification, thus obtaining four different specifications.

\subsection{Parameter Estimates}

Table 3 reports the estimates and standard errors of the underlying parameters of the model. ${ }^{27}$ The first two columns use the "Common Default Value", while the last two columns use the "Differentiated Default Value" where households derive different private benefits from defaulting on the bank contract depending on their specific characteristics. The odd columns of Table 3 restrict all households to face the same fixed cost (Common Cost) while even columns allow the the fixed cost to be household-specific (Differentiated Cost).

From Table 3, the distributional parameters share similarities across both specifications. One can easily obtain the distribution of scale $K$ and ability $z$ by using the log-normal distribution formulas. ${ }^{28}$ For the "Differentiated Default Value and Cost" specification, ability $z$ is distributed with mean 1.32 and variance 2.53 whereas the scale $K$ has mean 3.9 million Baht and a (large) variance of 220 million Baht. The implied

\footnotetext{
${ }^{27}$ The standard errors are computed using the outer product of the gradient (OPG) estimator. Since the ML estimation yields estimates that are functions of the parameters of interest, we use the Delta Method to obtain the desired standard errors.

${ }^{28}$ Suppose that $x=\log (X)$ and $y=\log (Y)$. Then if $(x, y)$ follow a bivariate normal distribution with parameters $\left(\mu_{x}, \mu_{y}, \sigma_{x}^{2}, \sigma_{y}^{2}, \rho\right)$, then the distribution of $X$ has mean $\mu_{X}=e^{\mu_{x}+\frac{\sigma_{x}^{2}}{2}}$ and variance $\sigma_{X}^{2}=e^{2 \mu_{x}+\sigma_{x}^{2}}\left(e^{\sigma_{x}^{2}}-1\right)$. Analogous expressions can be derived for $Y$. Finally, the coefficient of correlation

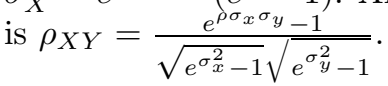


coefficient of correlation between $z$ and $K$ is -.43 . The estimated mean of scale $K$ is comparable to the mean wealth of 1.6 million Baht.

When the fixed cost of formal finance is common across households, it is estimated at 685 Baht (US\$28) or 311 Baht depending on the specification. It is never higher than 2 percent of the average formal loan size.

Table 3: Maximum Likelihood Estimates

\begin{tabular}{|c|c|c|c|c|c|c|c|c|}
\hline \multirow[b]{3}{*}{ Variable } & \multicolumn{4}{|c|}{ Common Default Value } & \multicolumn{4}{|c|}{ Differentiated Default Value } \\
\hline & \multicolumn{2}{|c|}{ Com. Cost } & \multicolumn{2}{|c|}{ Dif. Cost } & \multicolumn{2}{|c|}{ Com. Cost } & \multicolumn{2}{|c|}{ Dif. Cost } \\
\hline & Coef. & S.E. & Coef. & S.E. & Coef. & S.E. & Coef. & S.E. \\
\hline \multicolumn{9}{|l|}{ Distribution } \\
\hline$\mu_{\zeta}$ & -0.191 & 0.0125 & -0.221 & 0.0123 & -0.139 & 0.0128 & -0.165 & 0.0124 \\
\hline$\mu_{\kappa}$ & 0.981 & 0.0199 & 1.012 & 0.0197 & 0.895 & 0.0226 & 0.916 & 0.0220 \\
\hline$\sigma_{\zeta}$ & 0.969 & 0.0062 & 0.953 & 0.0061 & 0.966 & 0.0063 & 0.945 & 0.0059 \\
\hline$\sigma_{\kappa}$ & 1.561 & 0.0129 & 1.543 & 0.0127 & 1.610 & 0.0147 & 1.572 & 0.0140 \\
\hline$\rho$ & -0.870 & 0.0038 & -0.868 & 0.0038 & -0.844 & 0.0052 & -0.849 & 0.0049 \\
\hline \multicolumn{9}{|l|}{ Formal Access } \\
\hline Constant (in Baht) & 685.1 & 6.4 & $1,896.5$ & 52.8 & 311.3 & 2.4 & $1,643.5$ & 118.7 \\
\hline \multicolumn{2}{|c|}{ Formal Inst. in Village } & - & 0.369 & 0.0131 & & - & 0.592 & 0.0243 \\
\hline \multicolumn{2}{|c|}{ Past mem. Formal Inst. } & - & 0.800 & 0.0516 & & - & 0.669 & 0.0490 \\
\hline \multicolumn{2}{|c|}{ Past mem. Informal Inst. } & - & 1.741 & 0.2289 & & - & 1.033 & 0.1912 \\
\hline \multicolumn{2}{|c|}{ Member of Village Com. } & - & 1.275 & 0.1092 & & - & 0.844 & 0.0834 \\
\hline \multicolumn{2}{|l|}{ Education } & - & 1.030 & 0.0052 & & - & 0.968 & 0.0082 \\
\hline \multicolumn{2}{|c|}{ Savings in Formal Inst. } & - & 0.260 & 0.0099 & & - & 0.255 & 0.0128 \\
\hline \multicolumn{2}{|l|}{ Region } & - & 0.992 & 0.0222 & & - & 1.022 & 0.0501 \\
\hline \multicolumn{9}{|l|}{ Informal Access } \\
\hline Constant (in Baht) & 0.1 & 6.4 & 9.0 & 5.6 & 4.8 & 2.7 & 10.8 & 3.0 \\
\hline \multicolumn{9}{|c|}{ Enforcement Constraint } \\
\hline constant & & - & & - & 0.898 & 0.0018 & 0.917 & 0.0129 \\
\hline Num. Formal Inst. & n Vil. & - & & - & 0.985 & 0.0024 & 0.985 & 0.0031 \\
\hline Member of Vil. Con & & - & & - & 1.005 & 0.0076 & 0.993 & 0.0076 \\
\hline Sex of Head (Male) & & - & & - & 1.085 & 0.0028 & 1.072 & 0.0133 \\
\hline Education & & - & & - & 1.019 & 0.0003 & 1.024 & 0.0011 \\
\hline Region (Northeast) & & - & & - & 1.006 & 0.0033 & 0.984 & 0.0069 \\
\hline Number of Obs. & & 70 & 2,2 & & & 70 & & \\
\hline Likelihood & $-51,6$ & 47.04 & $-45,8$ & 9.40 & $-43,2$ & 84.36 & $-42,0$ & 56.29 \\
\hline
\end{tabular}


When the fixed cost of formal finance is allowed to vary across households, the intercept ranges from 1,897 Baht (US\$76) to 1,644 Baht depending on the specification. This still amount to less than 5 percent of the average formal loan size. This intercept is the cost per loan that a household would face if its vector of characteristics was zero in all the variables considered, which is hardly the case. The coefficients of these variables are shown in exponential form and are multiplicative of this constant term. Thus, if the coefficient is lower than one, the variable reduces the cost.

Education, social capital and the presence of a formal institution in the village significantly lower the cost of formal finance. Likewise, having savings with a formal institution also reduces the formal fixed cost, by roughly 74 percent. This seems to suggest that banks gain valuable information from offering non-loan services to their clients. In addition, having borrowed from a formal institution in the past also lowers the transaction cost, but this is not the case with informal borrowers. Hence, the data does not support the "syndication" argument developed in Jain (1999) and Conning (1996, 1998).

Although the data reject that the fixed cost of formal credit is uniform across households, the estimation reveals that this cost is nevertheless relatively small.

The transaction costs of informal finance are estimated at less than eleven Baht in all specifications. This finding complements the work of Siamwalla et al. (1993) also in Thailand or Udry (1993) and Aryeetey (1997) in Africa. These authors find that information asymmetries are unimportant within rural communities, and since informal lenders often live in the same village, they are easily accessible.

Table 3 also reports how household characteristics affect the value of defaulting on the bank loan contract. Education and having the head of the household be a male increase significantly the value of default. Contrary to the intuition that competition should lead to a tightening of credit constraints, households in villages with more formal institutions are less likely to face enforcement constraints. A likelihood ratio test between the different specifications is rejected at any common level of significance. Thus, the data also supports heterogeneity in the ability to default on a formal loan contract. 


\subsection{Goodness of Fit and Predictions}

Table 4 reports the average of the predicted fractions (in columns) for each actual borrowing choice (in rows) for the "Differentiated Default and Cost" specification. Thus, the diagonal elements of the matrix report the percentage of correct predictions.

Table 4: Goodness of Fit by Borrowing Choice

\begin{tabular}{lcccc}
\hline & Self-finance & Bank & Moneylender & Bank and Moneylender \\
\hline Self-finance & $\mathbf{5 4 . 0 9}$ & 26.02 & 6.31 & 13.58 \\
Bank & 57.58 & $\mathbf{2 7 . 0 7}$ & 2.08 & 13.27 \\
Moneylender & 39.60 & 32.91 & $\mathbf{7 . 6 1}$ & 19.88 \\
Bank and Moneylender & 48.76 & 31.56 & 2.49 & $\mathbf{1 7 . 1 9}$ \\
\hline \hline
\end{tabular}

Note: In Rows, reported choice, in Columns, predicted choice.

While the model is able to correctly predict more than half of the times the financial choice for households that self-finance, it does poorly in replicating households that report the other financial choices. The intuition for why the model assigns too much probability mass to the self-finance choice has to do with the ability to match simultaneously the financial choice and income. If the likelihood function only maximized the probability of the financial choice, more observations would be correctly predicted. ${ }^{29}$

We now use the estimates from the last specification to explore often households face a binding enforcement constraint. The model predicts that roughly 85 percent of the households that borrow from the bank are constrained, as it pays to borrow up to the constrained limit given that on average they face a relatively low fixed cost.

But how important are enforcement problems along with transaction costs overall? The top of Table 5 reports the predicted percentage average growth in income and investment that would result, respectively, without transaction costs but limited enforcement, perfect enforcement but transaction costs and no transaction costs and perfect enforcement, relative to the benchmark situation where enforcement is limited and transaction costs are present.

In the context of the data used, it is clear that government efforts should be devoted to policies that mitigate the enforcement problem, an issue to which we turn next.

\footnotetext{
${ }^{29}$ These results (available from the author upon request) appear in an earlier version of the paper.
} 
Table 5: Percentage Growth in Income and Investment

\begin{tabular}{lrr}
\hline & Investment & Income \\
\hline Relevance of Market Imperfections & & \\
Limited Enforcement, No Transaction Costs & 0.1 & 0.2 \\
Perfect Enforcement, Transaction Costs & 25.4 & 347.6 \\
Perfect Enforcement, No transaction Costs & 25.7 & 348.8 \\
Policy Analysis & & \\
5 percent cut in formal interest rate & 1.4 & 1.2 \\
Creation in formal institution in village & 0.1 & 0.1 \\
Land Titling Program & 15.2 & 201.5 \\
\hline \hline
\end{tabular}

Note: For each household, 1,000 $(z, K)$-pairs are simulated from the estimated distribution. Using each household's vector of characteristics and estimated parameters, the investment and income are computed under each scenario. Growth rates for each household and simulation are computed and the overall mean is reported.

\subsection{Policy Analysis}

The model is well suited to assess the impact of specific policies that have been used in the past to foster rural financial development. We first consider a policy of subsidized credit, where an interest rate ceiling is imposed below the market rate. We also consider a policy that focuses on the creation of village-level formal credit outlets. Finally we consider a land titling program. ${ }^{30}$ In terms of the model the first policy amounts to lowering the interest rate that formal institutions charge, the second that all households live in a village with a formal credit institution and the third to considering that all land can be used as collateral.

Two major caveats qualify the results. First, no attempt is made to quantify the costs of implementing such policies, so the results only indicate gross benefits. Second, we perform a partial equilibrium analysis in the sense that changes in one parameter or

\footnotetext{
${ }^{30}$ The first two types of policies have been analyzed extensively in the literature by the collection of articles in Von Pischke, Adams and Donald (1983), Braverman and Guasch (1986, 1993), Hoff and Stiglitz (1993), Besley (1994) and Yaron (1994). The land titling policy has been suggested by Feder et al. (1988) and Feder (1993). Although Thailand underwent a successful Land Titling Program, there are still rural areas, especially those close to Forest Reserves where no formal titles have been issued. See Giné (2004b) for more details.
} 
variable, do not affect others. ${ }^{31}$ Despite these shortcomings, the results reveal substantial differences in the impact of the policies considered.

Table 6: Percent Changes in Predicted Probabilities of Financial Choices

\begin{tabular}{lcccc}
\hline & $\mathrm{S}$ & $\mathrm{B}$ & $\mathrm{M}$ & $\mathrm{BM}$ \\
\hline 5 percent cut in formal interest rate & -0.92 & 2.92 & -2.49 & 0.49 \\
Creation of formal institution in village & -0.46 & 1.39 & -2.38 & 1.45 \\
Land Titling Program & -1.06 & 15.87 & -2.32 & -12.49 \\
\hline \hline Note: Financial Choices are Self-finance (S), Bank (B), Moneylender (M) \\
and Bank and Moneylender (BM).
\end{tabular}

Table 6 reports the percent changes in the predicted fraction of households making each financial choice for each policy considered relative to the benchmark estimation.

In a subsidized credit policy, the government is inducing agents to start up projects that at the previous interest rate were not profitable. This implies that the average entrepreneurial ability in the pool of formal loan applicants decreases. Although an interest rate reduction succeeds in drawing a larger fraction of households to the bank in detriment to the use of moneylenders, enforcement problems become more acute. ${ }^{32}$ In light of these numbers, it becomes clear why the literature has stressed the low repayment rates (or high default rates) associated with such a policy.

The creation of a formal institution in the village lowers effectively the transaction cost without affecting the pool of loans applicants at the low end. However, it does not alleviate enforcement problems, so once formal financing is more attractive (given the lower fixed cost), agents are more likely to be constrained and will resort to both formal and informal sources more often.

Only the land titling program succeeds in dramatically lowering the fraction of agents that resort to both sources of credit. If more assets can now be used as collateral, the bank will have less problems in advancing the unconstrained amount, and so informal finance is less needed.

\footnotetext{
${ }^{31}$ This can be problematic for the case of the interest rate charged by moneylenders. As studied in Hoff and Stiglitz (1997), a subsidized credit policy will have general equilibrium effects in the informal sector thereby altering the interest rate effectively charged by moneylenders.

${ }^{32}$ Indeed, one can check from Equation 6 that the loan size decreases with the formal interest rate.
} 
The bottom of Table 5 reports the average growth in income and investment resulting from the policies considered. Figure 6.3 complements Table 5 by displaying the conditional average income growth as a function of wealth.

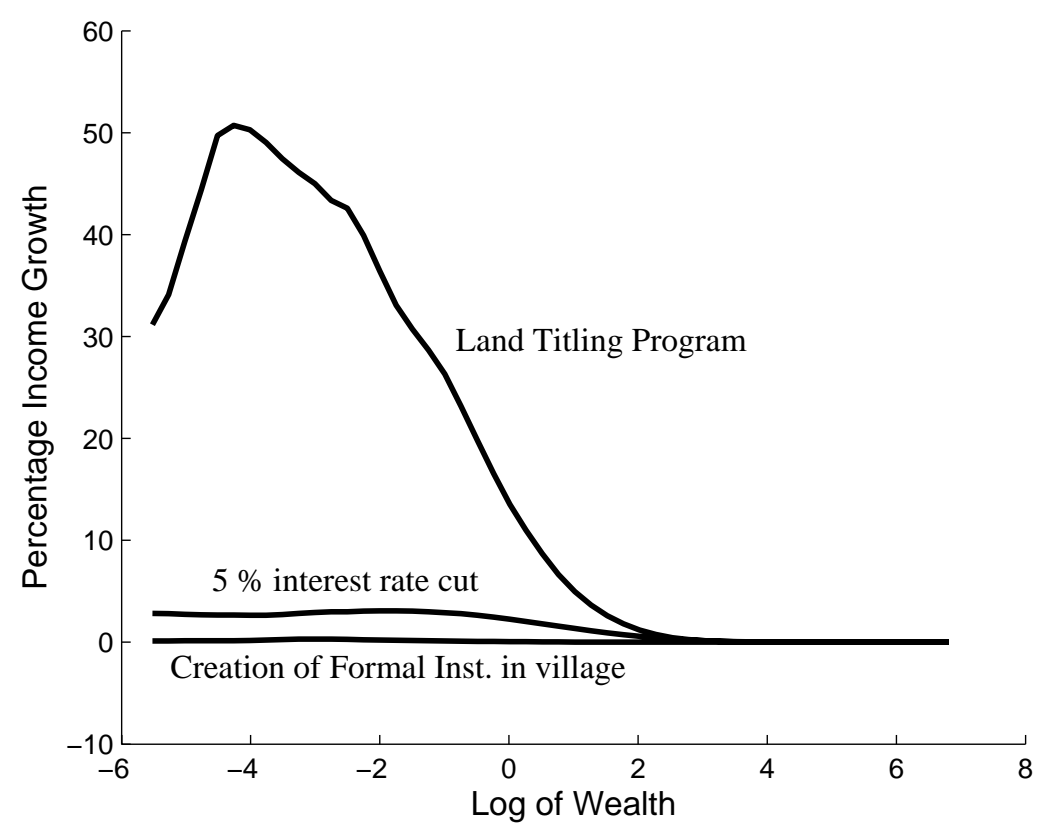

Figure 6: Percentage Income Growth from different Policies

\begin{abstract}
All household characteristics except wealth are set to the sample mean. For each observation, 1,000 $(z, K)$ pairs are generated, the income under the benchmark and the different policies is computed, as well as the average income growth. This (conditional on wealth) average income growth is then smoothed using local weighted regressions.
\end{abstract}

As expected, the land titling program has the largest impact given how important are enforcement constraints relative to the transaction costs considered. Notice also that those with some land holdings gain the most, while the richest do not benefit at all as they always self-finance.

\title{
7 Conclusions
}

This paper sheds light on the mechanism underlying access to credit when multiple lenders coexist. We construct and estimate a model based on limited enforceability and 
transaction costs, two important features of rural financial markets. The advantage of using a structural approach is twofold. First, we are explicit about the source of unobserved heterogeneity. This allows us to identify the parameters of the model given the data. Second, and most important, the model allows a quantitative assessment of different government policies often used in rural development.

Several points arise from the results. First, while the cost of accessing a formal institution are estimated at US\$30, informal lenders are accessible at no cost. Second, although this fixed cost of access to formal finance is not uniform across households, it is relatively small. Thus, the limited ability that formal institutions have to enforce contracts more than fixed transaction costs explain the diversity of lenders.

These transaction costs are incurred before the loan is taken and thus do not include expenses born by the lender to monitor while the loan is active, presumably recovered in the interest rate. In any event, using Banerjee's (2003) transaction costs taxonomy, we find that the estimated magnitude of the "ex-ante monitoring" expenses are not important.

If we compare the estimated setup to a frictionless one without transaction costs and perfect enforcement, average income would increase by 26 percent. This number seems to suggest that market imperfections are important and that there may be a role for government intervention. We thus provide some evidence as to why policies designed to provide cheap credit to rural households may not be effective as a land titling program, provided that the court system is efficient.

Obviously, lower interest rates as a result of efficiency gains in intermediation will increase the number of households resorting to formal institutions. This argument is, in fact, the main rationale for the presence of micro-finance institutions in rural areas as they take advantage of their innovative lending methodology.

But the point still remains that the key constraint to efficiency is the inability of formal lenders to enforce contracts. Therefore, success of policies that mitigate the enforcement problem seem to be warranted. 


\section{References}

I. Aleem. Imperfect Information, Screening, and the Costs of Informal Lending: A Study of a Rural Credit Market in Pakistan. In K. Hoff, A. Braverman, and J. Stiglitz, editors, The Economics of Rural Organization: Theory, Practice, and Policy, pages 131-153, New York, N.Y., 1993. Oxford University Press for the World Bank.

B. Armendáriz de Aghion and J. Morduch. The Economics of Microfinance. mimeo, New York University.

E. Aryeetey. Rural Finance in Africa: Institutional Developments and Access for the Poor. In Annual World Bank Conference on Development Economics 1996, pages 149-173, Washington, D.C., 1997. The International Bank for Reconstruction and Development/The World Bank.

A. Banerjee. Contracting Constraints, Credit Markets, and Economic Development. In M. Dewatripont, L. Hansen, and P. Turnovsky, editors, Advances in Economics and Econometrics - Theory and Applications, Eighth World Congress, Cambridge, U.K., 2003a. Cambridge University Press.

A. Banerjee. Do firms want to borrow more: Testing Credit Constraints using a targeted lending Program. BREAD working paper number 2003-5, 2003b.

C. Bell. Interactions between Institutional and Informal Credit Agencies in Rural India. In K. Hoff, A. Braverman, and J. Stiglitz, editors, The Economics of Rural Organization: Theory, Practice, and Policy, pages 186-213, New York, N.Y., 1993. Oxford University Press for the World Bank.

C. Bell, T.N. Srinivasan, and C. Udry. Rationing, Spillover and interlinking in Credit Markets: The Case of Rural Punjab. Oxford Economic Papers, 49:557-587, 1997.

T. Besley. How Do Market Failures Justify Interventions in Rural Credit Markets? The World Bank Research Observer, 9(1):27-47, 1994.

P. Bose. Formal-informal interaction in rural credit markets. Journal of Development Economics, 56:265-280, 1998.

A. Braverman and J. L. Guasch. Rural Credit Markets and Institutions in Developing Countries: Lessons for Policy Analysis from Practice and Modern Theory. World Development, 14(10/11):1253-1267, 1986. 
A. Braverman and J. L. Guasch. Administrative Failures in Government Credit Programs. In K. Hoff, A. Braverman, and J. Stiglitz, editors, The Economics of Rural Organization: Theory, Practice, and Policy, pages 53-69, New York, N.Y., 1993. Oxford University Press for the World Bank.

P.A. Chiappori and B. Salanié. Testing Contract Theory: A Survey of Some Recent Work. In M. Dewatripont, L. Hansen, and P. Turnovsky, editors, Advances in Economics and Econometrics - Theory and Applications, Eighth World Congress, Cambridge, U.K., 2003. Cambridge University Press.

J. Conning. Mixing and Matching Loans: Credit Rationing and Spillover in a Rural Credit Market in Chile. mimeo, Williams College, 1996.

J. Conning. Pirates and Moneylenders: Product-Market Competition and the Depth of Credit Relationships. mimeo, Williams College, 1998.

D. Evans and B. Jovanovic. An Estimated Model of Entrepreneurial Choice under Liquidity Constraints. Journal of Political Economy, 97:808-827, 1989.

G. Feder. The Economics of Land and Titling in Thailand. In K. Hoff, A. Braverman, and J. Stiglitz, editors, The Economics of Rural Organization: Theory, Practice, and Policy, pages 259-268, New York, N.Y., 1993. Oxford University Press for the World Bank.

G. Feder, T. Onchan, Y. Chalamwong, and C. Hongladarom. Land Policies and Farm Productivity in Thailand. John Hopkins University Press, Baltimore, Maryland, 1988.

M. Floro and D. Ray. Vertical Links between Formal and Informal Financial Institutions. mimeo, Boston University, 1996.

P. Ghosh and D. Ray. Information and Enforcement in Informal Credit Markets. IDE Discussion Paper series, number 93, Boston University, 1999.

X. Giné. Access to Capital in Rural Thailand: An Estimated Model of Formal vs. Informal Credit. mimeo, World Bank, 2004a.

X. Giné. Cultivate or Rent Out? Land Security in Rural Thailand. mimeo, World Bank, 2004b. 
X. Giné and R. Townsend. Evaluation of Financial Liberalization: A General Equilibrium Model with Constrained Occupation Choice. Journal of Development Economics, 74:269-307, 2004.

J. Greenwood and B. Jovanovic. Financial Development, Growth, and the Distribution of Income. Journal of Political Economy, 98:1076-1107, 1990.

L. Guiso, P. Sapienza, and L. Zingales. The Role of Social Capital in Financial Development. American Economic Review, 94(3):526-556, 2004.

J. J. Heckman. Statistical Models of Discrete Panel Data. In C. F. Manski and D. MacFadden, editors, Structural Analysis of Discrete Data with Econometric Applications, pages 114-178, Cambridge, MA., 1981. MIT Press.

K. Hoff and J. Stiglitz. Imperfect Information and Rural Credit Markets: Puzzles and Policy Perspectives. In K. Hoff, A. Braverman, and J. Stiglitz, editors, The Economics of Rural Organization: Theory, Practice, and Policy, pages 33-52, New York, N.Y., 1993. Oxford University Press for the World Bank.

K. Hoff and J. Stiglitz. Moneylenders and bankers: price-increasing subsidies in a monopolistically competitive market. Journal of Development Economics, 52:429-462, 1997.

A. Jain. Symbiosis vs. Crowding-Out: The Interaction of Formal vs. Informal Credit Markets in Developing Countries. Journal of Development Economics, 59:419-444, 1999.

N. Key. Modeling and Estimating Agricultural Household Behavior under Imperfect Markets. PhD thesis, University of California, Berkeley, Berkeley, California, 1997.

A. Kochar. An empirical investigation of rationing constraints in rural credit markets in India. Journal of Development Economics, 53:339-371, 1997.

A. Paulson and R. Townsend. Entrepreneurship and Financial Constraints in Thailand. Journal of Corporate Finance, 10:229-262, 2004.

A. Siamwalla, C. Pinthong, N. Poapongsakorn, P. Satsanguan, P. Nettayarak, W. Mingmaneenakin, and Y. Tubpun. The Thai Rural Credit System and Elements of a Theory: Public Subsidies, Provate Information, and Segmented Markets. In K. Hoff, A. Braverman, and J. Stiglitz, editors, The Economics of Rural Organization: Theory, 
Practice, and Policy, pages 154-185, New York, N.Y., 1993. Oxford University Press for the World Bank.

R. Townsend. Intermediation with Costly Bilateral Exchange. Review of Economic Studies, 45(3):417-425, 1978.

R. Townsend. Financial Structure and Economic Activity. American Economic Review, 73(5):895-911, 1983.

R. Townsend principal investigator with, A. Paulson, S. Sakuntasathien, T. Jeong Lee, and M. Binford. Questionnaire design and data collection for NICHD grant 'Risk, Insurance and the Family' and NSF grants. mimeographed, 1997.

C. Udry. Credit Markets in Northern Nigeria: Credit as Insurance in a Rural Economy. In K. Hoff, A. Braverman, and J. Stiglitz, editors, The Economics of Rural Organization: Theory, Practice, and Policy, pages 87-108, New York, N.Y., 1993. Oxford University Press for the World Bank.

J.D Von Pischke, D.W. Adams, and G. Donald. Rural Financial Markets in Developing Countries. The John Hopkins University Press for the World Bank, Baltimore, Maryland, 1983.

J. Yaron. What Makes Rural Finance Institutions Successful. The World Bank Research Observer, 9(1):49-70, 1994.

\section{A Data}

\section{Wealth of the Household $b$ and Scale $k$}

The scale $k$, at which the household operates its project, consists of all assets and inputs used in the production. This comprehensive measure includes the house, the current value of land-holdings, ponds, buildings, vehicles, equipment, livestock and other household, agricultural and business assets. Depending on the asset, households are asked the current or historical value of the asset. ${ }^{33}$ Following Paulson and Townsend (2004), if the

\footnotetext{
${ }^{33}$ Households report the current value of land-holdings, livestock and the house and the historical value of ponds and all other assets. Typical household assets include refrigerators, washing machines and furniture. Under agricultural assets one finds tractors, machinery and tools, and under business assets there are inventories, equipment and furniture.
} 
historical worth is given, we compute the current value by first converting the purchasing price to 1997 Baht using the Thai consumer price index, and then depreciating the asset at a 10 percent rate per year.

Wealth $b$ is the portion of the scale $k$ that is owned and is computed as the difference between scale $k$ and loans taken $l .{ }^{34}$ Without knowing whether the loan is spent, we would observe $k=\sum A_{i}$ if the loan is spent, where $A_{i}$ is the current value of a given asset $i$. We would then infer wealth by computing $b=k-l$. Analogously, if the loan is not spent, we would then observe $b=\sum A_{i}$ and estimate the scale as $k=b+l$. Although both approaches have obvious drawbacks, we assume that the loan is spent.

\section{Expected Income $y$}

According to the model, net income is $y=y^{e}+\delta k$, where $y^{e}$ is the reported expected net income. We use expected rather than realized because the model is deterministic. Fortunately, after the current net profit is elicited, the survey asks for an estimate of next year's net profit, which is the measure we use.

\section{Working to Total Capital $\eta$}

To determine whether an asset can be used as collateral, the model emphasizes the legal status, rather than the physical nature of the asset per se. But since working capital depreciates fully, all fixed capital is treated as if it could be used as collateral. For estimation purposes, we consider total capital investment as the sum of collateralizable fixed assets, uncollateralizable fixed assets and working capital, $k=k_{\text {uncol }}^{F}+k_{\text {col }}^{F}+k^{W}$. We divide fixed assets into $k_{\text {col }}^{F}$ and $k_{\text {uncol }}^{F}$ by running a regression of total amount pledged as collateral on a constant and the value of several types of assets owned by the household. We then compute our estimate of fixed capital that can be used as collateral $k_{\text {col }}^{F}$ as the sum of all assets that are statistically significant. Likewise, those assets not significant in the regression are added up into capital not used as collateral $k_{\text {uncol }}^{F}$. We use owned titled and non-titled land - cultivated and other -, ponds, buildings used for business and agricultural purposes and large vehicles such as tractors, trucks and pick-up trucks

\footnotetext{
${ }^{34}$ Given our interest in determining the cost of accessing credit, the loan amount $l$ is the sum of all outstanding loans. From the loans recorded in the survey, 63 percent were taken for productive purposes, 17.67 percent were consumption loans, 6.45 percent were used pay for ceremonies, educational and medical expenses, another 5.46 percent were used to re-lend or to repay past outstanding loans. The remaining 7.4 percent of the loans had other purposes. The category "productive purposes" includes loans to purchase or repair vehicles, buildings and equipment, as well as livestock and fertilizer, pesticide, herbicide and seeds.
} 
also used for business and agricultural purposes. ${ }^{35}$ Finally we include the value of other business and agricultural assets such as inventories, equipment, furniture, etc.

Table 7: Collateral Regression

\begin{tabular}{lrr} 
Variable & Coefficient & S.E. \\
\hline & $208521.3^{* * *}$ & 60917.1 \\
Constant & $0.1857^{* * *}$ & 0.0110 \\
Titled cultivated land & $0.0344^{* * *}$ & 0.0133 \\
Titled other land & 0.1637 & 0.1034 \\
Non-titled cultivated land & 0.2026 & 0.4125 \\
Non-titled other land & $7.3787^{* *}$ & 3.1625 \\
Ponds & 11.9807 & 5.2060 \\
Buildings for agricultural purposes & 4.9751 & 2.9426 \\
Vehicles for agricultural purposes & 4.5004 & 6.2188 \\
Buildings for business purposes & 7.6871 & 7.0247 \\
Vehicles for business purposes & -7.0480 & 12.0867 \\
Livestock & 0.4457 & 2.2325 \\
Other business assets & -0.7603 & 1.8784 \\
Other agricultural assets & \multicolumn{2}{c}{737} \\
& 0.3422 \\
\hline Number of Observations & \multicolumn{2}{c}{} \\
Adjusted $R^{2}$ & \\
\hline \hline Note: The symbol ${ }^{* * *}$ and ${ }^{* *}$ indicate that the variable is \\
significant at the 1 and 5 percent level, respectively. The \\
dependent variable is the value of assets pledged as collateral \\
for loans that required collateral. The regression is estimated \\
using OLS methods. \\
Source: Townsend-Thai Data.
\end{tabular}

Confirming the common practice of banks, our estimate of fixed capital used as collateral includes all titled land (cultivated and other), ponds and buildings for agricultural purposes. $^{36}$

\footnotetext{
${ }^{35}$ As described in Feder et al. (1988) and Giné (2004), the Thai Government issues different land property documents depending on the legal status, transfer rights and other stipulations. For our purposes, it is important to note that not all land titles are used as collateral.

${ }^{36}$ The coefficient of "Buildings for agricultural purposes" is high because what is actually being pledged as collateral is the land on which the measured structure is located. Given that the building structure is of little value (compared to the land), the coefficient is high.
} 
The ratio $\eta$ is the fraction of capital that banks cannot seize, and it is computed as:

$$
\eta=1-\frac{k_{\mathrm{col}}^{F}}{k}
$$

The fraction of total non-depreciated capital is no longer $\delta=\tilde{\delta}(1-\eta)$, because this expression assumes that fixed capital that cannot be used as collateral depreciates fully. Rather, the parameter $\delta$ is computed as

$$
\delta=\tilde{\delta} \frac{k_{\mathrm{uncol}}^{F}+k_{\mathrm{col}}^{F}}{k}
$$

\section{B Analytical derivation of the Finance Map}

In this appendix we provide a closed form solution for the different cutoff curves. The segments denoted $K_{M}^{S}(z)$ are found by equating the net incomes from self-financing $Y_{S}$ with borrowing from a moneylender $Y_{M}$ and solving for the scale $K$. We obtain

$$
\left(z+\delta-r_{M}\right)(K-b) \geq \Gamma_{M} \quad \text { or } \quad K_{M}^{S}=b+\frac{\Gamma_{M}}{z-r_{M}+\delta} .
$$

The vertical segment at ability $z_{S}^{B c}$ is found be equating $Y_{S}$ and the net income from borrowing from a bank and being constrained $Y_{B c}$. This yields a quadratic expression in ability $z$ that does not depend on the scale $K$ :

$$
b \geq \frac{\Gamma_{B}}{z+\delta-\eta}\left[\frac{\eta}{z+\delta-r_{B}}-1\right] .
$$

Given that when $\Gamma_{B}=0$, the positive root is $z=r_{B}-\delta$ and the negative is $z=\eta-\delta$, the positive is chosen because it satisfies $z \geq r_{B}-\delta$, a necessary condition for optimal investment to be positive.

Finally, the segment denoted $K_{B u}^{S}(z)$ comes from equating the net incomes from self-finance $Y_{S}$ with going to the bank and obtaining unconstrained credit $Y_{B u}$.

$$
\left(z+\delta-r_{B}\right)(K-b) \geq \Gamma_{B} \quad \text { or } \quad K_{B u}^{S}(z)=b+\frac{\Gamma_{B}}{z-r_{B}+\delta} .
$$


Note that the expressions in Equations 13 and 15 are very similar. Next, the cutoff level $K_{M}^{B u}(z)$ is found by equating net income of unconstrained borrowing from the bank $Y_{B u}$ with the net income of resorting to a moneylender $Y_{M}$. This yields

$$
b \leq K-\frac{\Gamma_{B}-\Gamma_{M}}{r_{M}-r_{B}} \quad \text { or } \quad K_{M}^{B u}(z)=b+\frac{\Gamma_{B}-\Gamma_{M}}{r_{M}-r_{B}}
$$

which does not depend on the ability $z$. The cutoff curve $K^{E C}(z)$ is precisely $k^{c}$ in Equation 6 and divides agents into those that will obtain a constrained amount from those that will receive the unconstrained maximum capacity $K$.

The curve $K_{B c}^{B M}(z)$ is found by equating the net incomes $Y_{B c}$ and $Y_{B M}$. This yields a quadratic expression in $z$,

$$
\Gamma_{M} \geq\left(z+\delta-r_{M}\right)\left[K-\frac{b r_{B}}{\eta-\left(z+\delta-r_{B}\right)}\right]
$$

which in terms of $K$ can be rewritten as

$$
K_{B c}^{B M}(z)=\frac{\Gamma_{M}}{z+\delta-r_{M}}+\frac{b r_{B}}{\eta-\left(z-r_{B}+\delta\right)} .
$$

Finally, we need to compare the net income $Y_{B c}$ with the net income $Y_{M}$ on the one hand, and $Y_{M}$ with $Y_{B M}$ on the other, delivering the curve $K_{B c}^{M}(z)$ and the cutoff ability $z_{M}^{B M}$ respectively. Therefore, comparing $Y_{B c}$ with $Y_{M}$ we obtain

$$
\frac{\eta b r_{B}}{\eta-\left(z-r_{B}+\delta\right)-\Gamma_{B}}=z K-(K-b) r_{M}+\delta K-\Gamma_{M}
$$

or in terms of $K$,

$$
K_{B c}^{M}(z)=\frac{1}{z+\delta-r_{M}}\left[\frac{b \eta r_{B}}{\eta-\left(z-r_{B}+\delta\right)}-b r_{M}-\left(\Gamma_{B}-\Gamma_{M}\right)\right] .
$$

Now comparing $Y_{M}$ with $Y_{B M}$ we get

$$
b\left[\frac{r_{B}}{\eta-\left(z-r_{B}+\delta\right)}-1\right]=\frac{\Gamma_{B}}{r_{M}-r_{B}}
$$


which does not depend on $K$. Solving for $z$, we obtain,

$$
z_{M}^{B M}=\eta-\delta+\frac{\Gamma_{B} r_{B}}{\Gamma_{B}+b\left(r_{M}-r_{B}\right)} .
$$

This completes the characterization of the cutoff curves in Figure 3 in the text.

\section{B.1 Proof of Proposition 1}

The goal is to show that for certain values of wealth, some regions that appear in Figure 3 merge or disappear altogether. We assume throughout that $0 \leq \eta \leq 1$ and $r_{M}>r_{B}>1$.

First, we check when regions $\mathbf{M}$ and $\mathbf{B M}$ exist. For this, we find all ability levels $z$ such that $K_{B c}^{M}(z)=K_{B c}^{B M}(z)$. From Equations 18 and 20 or the map in Figure 3 we know that $z_{M}^{B M}$ in Equation 22 is a root. In addition, $z_{a}=r_{M}-\delta$ and $z_{b}=r_{B}+\eta-\delta$ are also roots.

Note that $z_{b}>z_{a}$ as long as $\eta>r_{M}-r_{B}$. Thus, regions $\mathbf{M}$ and $\mathbf{B M}$ will disappear if $\eta \leq r_{M}-r_{B}$. In addition, it is always the case that $z_{b}>z_{M}^{B M}$ because $r_{M}>r_{B}$ and $b \geq 0$ by assumption. Finally, the top region $\mathbf{M}$ will exist if (and only if) $z_{M}^{B M}>z_{a}$. Some algebra indicates that this condition, as assumed in Figure 3, is satisfied as long as

$$
b<\frac{\Gamma_{B}\left[\eta-\left(r_{M}-r_{B}\right)\right]}{\left(r_{M}-\eta\right)\left(r_{M}-r_{B}\right)}=\tilde{b}
$$

We now want to determine when the two region $\mathbf{M}$ in Figure 3 merge. It is useful to define abilities $z_{M, B u}^{E C}$ and $z_{M}^{B u}$ as the level of ability $z$ such that $K^{E C}(z)=K_{M}^{B u}(z)$ and $K_{S}^{B u}(z)=K_{S}^{M}(z)$ respectively. Some algebra yields

$$
z_{M, B u}^{E C}=\eta-\delta+\frac{r_{B}\left(\Gamma_{B}-\Gamma_{M}\right)}{b\left(r_{M}-r_{B}\right)+\Gamma_{B}-\Gamma_{M}} \quad \text { and } \quad z_{M}^{B u}=\frac{\Gamma_{B} r_{M}-\Gamma_{M} r_{B}}{\Gamma_{B}-\Gamma_{M}}-\delta .
$$

It turns out that both regions merge whenever $z_{M, B u}^{E C}>z_{M}^{B u}$. We can write this last condition solving for wealth $b$ as

$$
b<\left[\frac{\Gamma_{B}-\Gamma_{M}}{r_{M}-r_{B}}\right] \frac{\Gamma_{B}\left(r_{B}-r_{M}\right)+\eta\left(\Gamma_{M}-\Gamma_{B}\right)}{\Gamma_{B}\left(r_{M}-\eta\right)-\Gamma_{M}\left(r_{B}-\eta\right)}=\hat{b}
$$


Finally, one can show by combining the expressions in (23) and (25) that $\hat{b}<\tilde{b}$ always.

The panels in Figure 7 show the different maps described in Proposition 1. Financial choices are depicted with solid thick lines, while the different numbered integrals that partition the regions and the dotted thick line are explained in the next Appendix section.
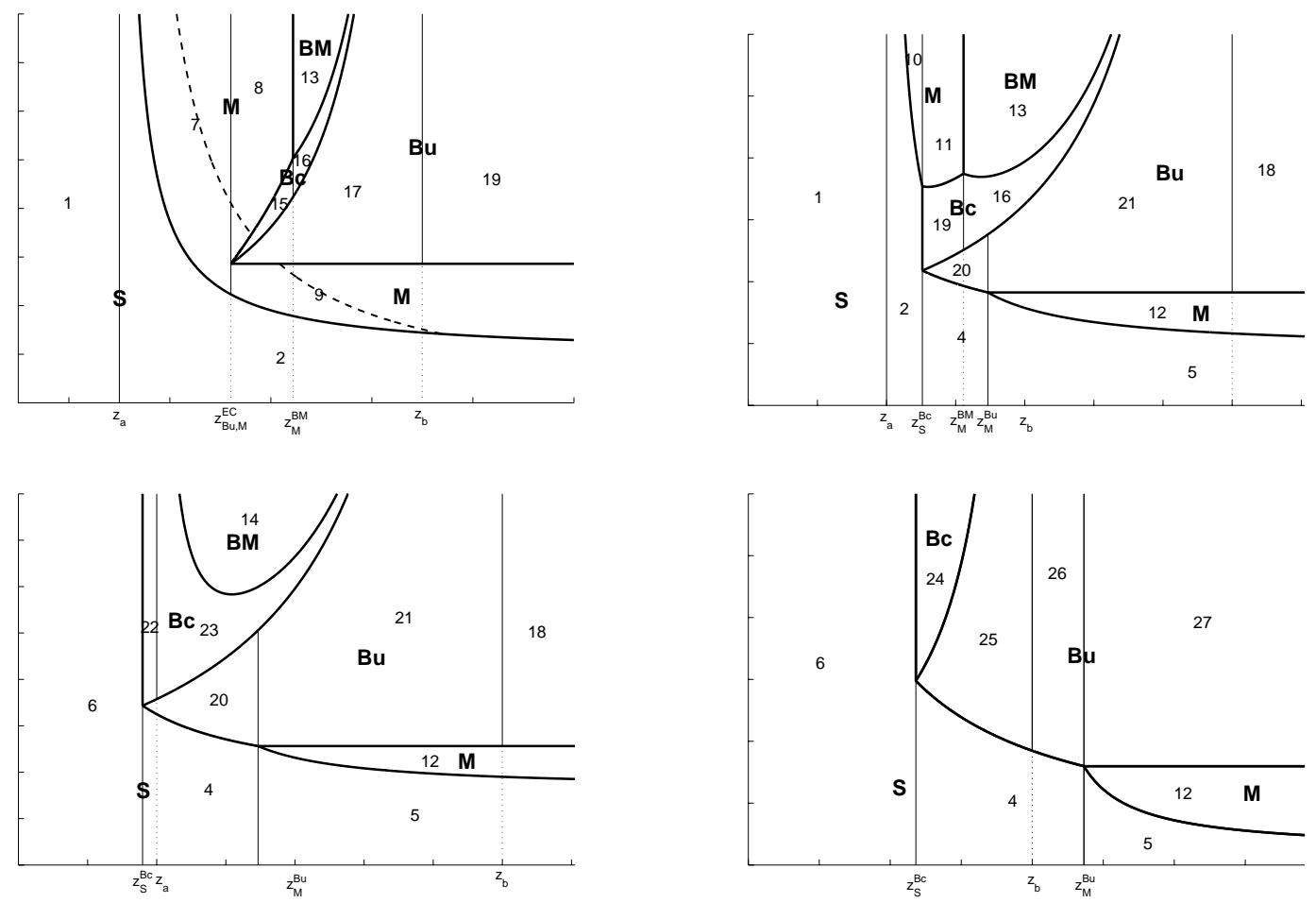

Figure 7: Maps of: Prop 1.i) (top left), Prop 1.ii) (top right), Prop 1.iii) (bottom left) and Prop 1.iv) (bottom right)

The solid thick lines mark financial choices, while solid thin lines separate integrals. The dotted thick line in Top left Panel plots the function $K_{M}^{Y}\left(y_{i}, z\right)$ for a given $y_{i}$. 


\section{Likelihood Function}

For an entrepreneur with income $Y=y_{i}$, financing decision $L=l_{i}$ and characteristics $\nu_{i}$, the likelihood can be obtained using Bayes Law as,

$$
f\left(y_{i}, l_{i} \mid \nu_{i}, \theta\right)=\operatorname{Pr}\left[Y=y_{i} \mid L=l_{i}, \nu_{i}\right] \times \operatorname{Pr}\left[L=l i \mid \nu_{i}\right]
$$

Using the fact that net income $y_{i}=y(z, K)$ is a function of the unobserved variables, we can solve for $K_{i}=K\left(y_{i}, z\right)$. The first term of (26) can thus be written as

$$
\operatorname{Pr}\left[Y=y_{i} \mid L=l_{i}, \nu_{i}\right]=\int_{\zeta \in \mathcal{Z}_{l_{i}}} h\left(\zeta, \kappa\left(y_{i}, \exp (\zeta)\right)\right) d \zeta
$$

where $h(\zeta, \kappa)$ denotes the joint density of the log ability $\zeta$ and $\log$ scale $\kappa$ and the set $\mathcal{Z}_{l_{i}}$ contain all points in the domain of $\zeta$ where $l_{i}$ is the optimal financial choice. The second term in the RHS of (26) is the probability of a given financial choice $L$ :

$$
\operatorname{Pr}\left[L=l i \mid \nu_{i}\right]=\int_{\zeta \in \mathcal{Z}_{l_{i}}(\kappa)}\left[\int_{\kappa \in \mathcal{K}_{l_{i}}(\zeta)} h(\zeta, \kappa) d \kappa\right] d \zeta
$$

where now the sets $\mathcal{Z}_{l_{i}}(\kappa)$ (or $\mathcal{K}_{l_{i}}(\zeta)$ ) contain all points $\zeta$ (or $\kappa$ ) making $l_{i}$ optimal with variable $\kappa$ (or $\zeta$ ) held fixed.

As an example, consider an entrepreneur with reported expected income $y_{i}$, financial choice $l_{i}=M$ and wealth $b$ such that $b<\hat{b}$, so that she is facing the top left panel of Figure 7.

The likelihood for this entrepreneur is

$$
\operatorname{Pr}\left[Y_{M}=y_{i}, l_{i}=M \mid \nu_{i}\right]=\operatorname{Pr}\left[Y_{M}=y_{i} \mid l_{i}=M, \nu_{i}\right] \times \operatorname{Pr}\left[L=M \mid \nu_{i}\right]
$$

The first part of Equation 29 is

$$
\operatorname{Pr}\left[Y_{M}=y_{i} \mid l_{i}=M, \nu_{i}\right]=\int_{\zeta>\log \left(r_{M}-\delta\right)} h\left(\zeta, \kappa_{M}^{Y}\left(y_{i}, \exp (\zeta)\right)\right) d \zeta
$$

where

$$
\kappa_{M}^{Y}\left(y_{i}, \exp (\zeta)\right)=\kappa_{M}^{Y}\left(y_{i}, z\right)=\log \left(\frac{y_{i}+\Gamma_{M}-r_{M} b}{z+\delta-r_{M}}\right)
$$


The function $\kappa_{M}^{Y}\left(y_{i}, z\right)$ is the dotted thick line at the top left panel of Figure 7 . It represents the scale $K$ as a function of $z$ that yields $y_{i}$ as net income when the financial choice is $l_{i}=M$.

The second term of the likelihood in Equation 29 is the integral of the joint density $h(\zeta, \kappa)$ under the regions 7,8 and 9 , corresponding to Region $\mathbf{M}$ (also in the top left panel of Figure 7.

The double integral in Equation 28 can be rewritten using the fact that log ability $\zeta$ and $\log$ scale $\kappa$ follow a bivariate normal distribution:

$$
\kappa \mid \zeta \sim N\left(\alpha_{\zeta}+\beta \zeta,\left(1-\rho^{2}\right) \sigma_{\kappa}^{2}\right), \quad \text { where } \quad \alpha_{\zeta}=\mu_{\kappa}-\beta \mu_{\zeta} \quad \text { and } \quad \beta=\rho \frac{\sigma_{\kappa}}{\sigma_{\zeta}}
$$

Thus,

$$
\begin{aligned}
\operatorname{Pr}\left(L=l_{i} \mid \nu_{i}\right) & =\int_{\zeta \in \mathcal{Z}_{l_{i}}(\kappa)} \phi\left(\frac{\zeta-\mu_{\zeta}}{\sigma_{\zeta}}\right)\left[\int_{\kappa \in \mathcal{K}_{l_{i}}(\zeta)} \phi\left(\frac{\kappa-\alpha_{\zeta}-\beta \zeta}{\sqrt{1-\rho^{2}} \sigma_{\kappa}}\right) d \kappa\right] d \zeta \\
& =\int_{\tilde{\zeta} \in \mathcal{Z}_{l_{i}}(\tilde{\kappa})}\left[\Phi\left(\widetilde{\widetilde{\kappa}}_{l_{i}}(\tilde{\zeta})\right)-\Phi\left(\widetilde{\kappa}_{l_{i}}(\tilde{\zeta})\right)\right] \phi(\tilde{\zeta}) d \tilde{\zeta}
\end{aligned}
$$

where $\phi$ and $\Phi$ denote, respectively, the probability and cumulative densities of a standard normal distribution. In addition, $\widetilde{\kappa}_{l_{i}}(\tilde{\zeta})$ is short-form notation for

$$
\widetilde{\kappa}_{l_{i}}(\tilde{\zeta})=\frac{\kappa_{l_{i}}(\tilde{\zeta})-\alpha_{\zeta}-\beta\left(\mu_{\zeta}+\sigma_{\zeta} \tilde{\zeta}\right)}{\sqrt{1-\rho^{2}} \sigma_{\kappa}}=\frac{\kappa_{l_{i}}(\tilde{\zeta})-\mu_{\kappa}-\rho \sigma_{\kappa} \tilde{\zeta}}{\sqrt{1-\rho^{2}} \sigma_{\kappa}}
$$

so that a tilde in a variable denotes the normalized variable. Clearly, $\bar{\kappa}_{l_{i}}(\zeta)$ and $\underline{\kappa}_{l_{i}}(\zeta)$ are bounds such that given $\log$ ability $\zeta$, the financial choice $l_{i}$ is optimal for any $\kappa \in$ $\left[\underline{\kappa}_{l_{i}}(\zeta), \bar{\kappa}_{l_{i}}(\zeta)\right]$.

We compute the integral in Equation 31 above by partitioning it into different subintegrals with general support $[a, b]$ and possibly $[a, \infty)$. These sub-integrals are numbered in Figure 7. We approximate numerically each integral with support $[a, b]$ using Gauss-Legendre quadrature with 48 points in $[-1,1]$ with an appropriate change of scale. Analogously, integrals with support $[a, \infty)$ are approximated using Gauss-Laguerre with 48 points in $[0, \infty)$. 